\title{
Study of the Complexity Game of Supply Chain Green Innovation Introduction under EPR Policy and Government Subsidies
}

\author{
Xueli Zhan $\left(\mathbb{D},{ }^{1,2}\right.$ Yi Tian $\left(\mathbb{D},{ }^{1}\right.$ Chengjin Liu $\left(\mathbb{D},{ }^{1}\right.$ Aili Hou $\left(\mathbb{D},{ }^{1}\right.$ and Junhai Ma $\mathbb{D}^{1}$ \\ ${ }^{1}$ College of Management and Economics, Tianjin University, Tianjin 300072, China \\ ${ }^{2}$ School of Economics, Beijing Wuzi University, Beijing 101149, China \\ Correspondence should be addressed to Yi Tian; yit20160831@126.com and Chengjin Liu; liuchengjin@tju.edu.cn
}

Received 10 March 2020; Revised 23 June 2020; Accepted 13 July 2020; Published 9 September 2020

Guest Editor: Tomas Veloz

Copyright (c) 2020 Xueli Zhan et al. This is an open access article distributed under the Creative Commons Attribution License, which permits unrestricted use, distribution, and reproduction in any medium, provided the original work is properly cited.

Nowadays, with global scientific and technological levels rapidly improving, innovation has been a great need for enterprises to solve the dilemma. Combined with EPR (Extended Producer Responsibility) and the topic of remanufacturer, adopting green innovation has been an effective way when green supply chain management is applied. In this paper, we focus on the activity of green innovation and build a model where the manufacturer will invest in green innovation to improve the product availability rate of recycled products and save the cost in the process of remanufacturing. Besides, we take three stages in a cycle into consideration, that is, production/sale, recycling used production, and remanufacture/sale, and meanwhile, the government gives a subsidy to enterprises to encourage the activity of recycling. In the process of model solving, we take a dynamic decision-making way into consideration. We find that the decision adjustment speed of players has a significant effect on the stability, and in a long dynamic repeated game process, with the speed of decision adjustment increasing, the system enters into chaos at the end of the process. It is interesting that when the speed of decision adjustment exceeds the critical point of the bifurcation diagram, the profit of the manufacturer decreases and then enters a chaotic state. Besides, with the level of subsidies increasing, the area of stable region decreases gradually. Certain investment has a positive effect on product selling and recycling as well as the profit, and the government subsidy undoubtedly raises the profit of manufacturers and encourages the activity of recycling. In the end, we make chaos control by adjusting the decision method.

\section{Introduction}

Due to the increasing environmental preoccupation, the potential economic benefits, and the legislation pressure, supply chain management has changed to focus on environmental impacts of production and Earth resources' preservation [1]. More and more emphases have been put on a closed-loop supply chain because of its benefit of recycling processes which are the possibility of economic viability and environmental sustainability [2]. As we all know, closed-loop supply chain contains two parts, the forward supply chain and the reverse supply chain, in which the new product development, product design and engineering, procurement and production, marketing, sales, distribution, and after-sale service are realized in the forward supply chain, and then, the reverse supply chain refers to used products' collection, testing, sorting, refurbishing, recovery, recycling, remarketing, reselling, and so on $[3,4]$. The closed-loop supply chain expands the connotation of the traditional supply chain and realizes protecting the environment because it increases the utilization ratio of raw materials and reduces the emission levels. Based on that, the closed-loop supply chain has become a new trend in logistics and supply chain management. In China, the EPR pilot work carried out by the Ministry of Industry and Information Technology, Ministry of Finance, Ministry of Commerce, and Ministry of Science and Technology continues to progress, and the EPR recycling has also achieved periodic results.

Remanufacturing is an important part of the closed-loop supply chain which makes resource sustainable possibly. Remanufacturing is the process in which a used product transforms into a "new" product or into a product satisfying 
quality level that meets the recently approved American National Standards Institute definition for remanufacturing [5]. Remanufacturing expands the concept of "product life cycle" which usually refers to product manufacturing, use, and disposal. After the birth of the remanufacturing industry, besides the three phases we said, product maintenance and using advanced remanufacturing technology to repair and reconstruction are also needed to be considered in the product design. The USA is the largest remanufacturer in the world, and the output rose 15 percent to at least $\$ 43$ billion, supporting 180,000 full-time US jobs by remanufacturing between 2009 and 2012. So, remanufacture benefits not only the environment but also the development of economic. In 2008, the Chinese National Development and Reform Commission launched a pilot program of auto part remanufacturing, and 14 firms were selected and supported to start up remanufacturing, seven of which are auto manufacturers (or their subsidiaries) and the others even are part suppliers [6].

Nowadays, with global scientific and technological levels rapidly improving and to reply to the pressures from customers, competitors, and regulators, innovation has been a great need for enterprises $[7,8]$. So, combined with the topic of remanufacturing, adopting green innovation is becoming so important when green supply chain management is applied. Based on what we refer to, the questions we try to answer can be shown as follows. First of all, considering the government's financial intervention and the competition in the market, does a manufacturer need to invest in green innovation to improve the product availability rate of recycled products? Then, how about taking a dynamic decision-making way into consideration? How will product prices evolve in repeated games? What will happen to the stable domain? Besides, what can we do to control chaos?

So, innovation in this paper can be concluded as follows. In our model, we take recycling and remanufacturing into consideration, and there are three stages in a cycle, that is, production/sale, recycling used production, and remanufacture/sale. Then, combined with the recycling of used products, we take manufacturer and supplier into consideration and answer the question of whether a manufacturer needs to invest in green innovation to improve the product availability rate of recycled products. Besides, based on the complex system theory, we take a dynamic decision-making way into consideration instead of limitations into a single period static decision. In the end, the way of controlling chaos is discussed.

The rest of this paper is organized as follows. In Section 2 , we review the relevant literature. In Section 3, we describe the problem and show the symbols and assumptions of our model. In Section 4, we build and solve the model and get equilibrium points. Results are also analyzed. In Section 5, through the numerical simulation, we get the bifurcation diagram and stability domain diagram to express chaos. In Section 6, chaos control is made. In the end, we provide the conclusions in Section 7.

\section{Literature Review}

Innovation pushes society and economics toward development, and under the background of environmental protection and sustainability, green innovation is becoming more and more essential. A lot of literature has researched green innovation investment in recent years. Xie et al. [9] built a dynamic model using data of 28 industries in 10 years and studied green process innovation from the perspective of the financial performance of the manufacturing industry. Ley et al. [10] researched the relationship between energy prices and green innovation activities from an industry level. Olson [11] took the green innovation value chain (GIVC) as the tool to analyze the financial feasibility of green products from the perspective of multiple stakeholders. What has been expressed in many studies is that pressure from regulators has a positive effect on green product innovation [12]. Sheu and Chen [13] also verified that governmental financial intervention has a positive effect on the green profit of the enterprise. Then, Ashkan [14] further expressed the benefit of governmental financial intervention. Generally speaking, there are three kinds of governmental financial interventions which are subsidy, taxes, and insurance $[13,15,16]$. Under a threestage game framework, Subrata [17] established centralized and decentralized conservation models to gain a fair understanding of the advantages of government subsidies to consumers and manufacturers. By comparing the profit, greening level, consumer surplus, and environmental improvement of each member under two different incentive policies, Nielsen et al. [18] came up with a decision support framework for the selection and successful implementation of environmentally friendly products is obtained. At the same time, Izabela Ewa [18] also compared three kinds of government policies to study issues such as government subsidy policy with optimal pricing in the closed-loop supply chain, investment decision to improve product quality, and product recycling under the goal of social welfare optimization. Huang et al. [19] established a series of game models to study the impact of green loans and government subsidies on enterprises' green innovation activities. Inspired by the above studies, we build a closed-loop supply chain and research the investment of green innovation considering governmental financial intervention.

The closed-loop supply chain has raised much attention from more and more scholars. Remanufacturing is an important process of the closed-loop supply chain that has been put more and more emphasis on. In the study of remanufacturing and closed-loop supply chain management, competition between new and remanufactured products, inventory management, quality, pricing, and who carries out recycling and remanufacturing activities are the five main issues [3, 20-22]. Maiti and Giri [22] built a closed-loop supply chain in which a manufacturer produces new products and sells them to the retailer; besides, he also produces remanufactured products and sells them to the secondary market. They analyzed the model under four different decision structures and got the optimal decision. Turki et al. [1] considering manufacture, remanufacture, transportation, and warehouse built a closed-loop supply chain model and used simulation to obtain the optimal values of decision variables. Hong et al. [2] verified the effect 
of technology licensing on supply chain members' decision. And they built a two-period closed-loop supply chain in which, as for the patent holder, the manufacturer produces new and remanufactured products and, as for the licensee, a remanufacturer collects used products and produces remanufactured products at the same time. Giovanni and Zaccour [3] built a two-period closed-loop supply chain and analyzed whether the remanufacturer should outsource the collection of the used products to the retailer. Hosoda and Disney [23] researched the dynamics of a closed-loop supply chain and got the optimal decision to minimize inventory costs of the manufacturer. Li et al. [20] analyzed the relationship between product quality improvement and remanufacturing making by a monopolist manufacturer. However, there are a lot of studies we can access to discuss remanufacturing, but few scholars researched that supplier is responsible for remanufacturing. Then, we take inspiration from [6] who researched the question about whether the supplier or manufacturer remanufactures in a closed-loop supply chain and built a closed-loop supply chain to discuss who would invest in green innovation and remanufacture on the component level. Tang et al. [24] conducted a Stackelberg game to examine pricing and warranty decisions under two warranty models, which consist of a manufacturer and a retailer. Li et al. [25] have a study about the investigations of product design and its impact on the operations of a twoechelon closed-loop supply chain. Wang et al. [26] examined the benefit of the reward-penalty mechanism in a two-period closed-loop supply chain and analyzed by game models.

By analyzing the above literature, we can find that most scholars assume that the manufacturers are entirely rational. However, in a long time, supply chain members' decision stage is a dynamic process. They have imperfect information about the market and are bounded rational. So, we introduce nonlinear dynamics theory as a solution. Nonlinear dynamics theory is an effective tool theory and has been widely researched. Bao and Ma [27] studied the quantity decision by considering the product quality in parallel supply chains where two manufacturers produce substitute products and then sell them to their downstream retailers separately; the alternatives are analyzed. Ma and Guo [28] applied nonlinear dynamic theory with different adjustment mechanisms and expectations in a supply chain and analyzed the impacts of key parameters on the stability of the positive Nash equilibrium point. Ma et al. [29] built a closed-loop supply chain model with dual-channel recycling composed of one manufacturer and one-third-party, made a number of simulations $[7,30]$, analyzed macroeconomic models with Hopf bifurcation theory, and found some phenomenon in these nonlinear dynamic models. Ma and Xie [31] aimed at the color TV recycling market, built the model, and researched related parameters' effect on the system's stability; in the end, they made chaos control. Dai et al. [32] constructed a continuous dual-channel closed-loop supply chain model with the delayed decision under government intervention. They analyzed the related parameters' influence and used delay feedback control method to control the chaos.

\section{Model Construction}

In this work, we focus on the activity that the manufacturer will invest in green innovation to realize remanufacturing considering government financial intervention. As we all know, extended producer responsibility system, which refers to the responsibility that the producer needs to take not only in the production process but also in the entire life cycle, especially the recycling and disposal, has been recognized by many countries. So based on this, we build a model containing two manufacturers, one of which invests in green innovation, and we take recycling and remanufacturing into consideration. In the first stage, manufacturers produce new products and sell them to consumers; in the second stage, manufacturers, respectively, collect used products they produced from consumers; in the third stage, manufacturers will remanufacture. The whole stages constitute a cycle of production activities in the supply chain. Meanwhile, one of the manufacturers invests in green innovation to improve the product availability rate of recycled products which means that, as for a product, the proportion of its reusable component increases and the manufacturer saves cost during remanufacturing.

The timeline of decision-making is as follows: the activities of a whole cycle can be expressed as three stages and the two manufacturers move simultaneously. In stage 1, manufacturers produce new products, set prices, and then sell them to the market. Manufacturer 1 decides the green innovation level and invests in this stage. In stage 2, manufacturers recycle used products, respectively. In stage 3, manufacturers remanufacture recycled products and sell them to customers again. The timeline of the decisionmaking process can be described in Figure 1 .

In our model, two manufacturers produce two kinds of homogeneous products and the price of new products produced by two manufacturers in the period $t(t=1,2,3, \ldots)$ is $p_{1}(t)$ and $p_{2}(t)$. They compete in the market and we use $\theta$ which belongs to $(0,1)$ for the degree of substitution between two kinds of similar products; these assumptions are similar to some existing papers (such as Xie and Ma, Ma et al. [33], and Ma et al. [29]). In this market, we assume that customers prefer purchasing products having a low price, and the sensitivity to price can be captured by $b$. So, the demand function of each kind of product in the period $t$ is shown as follows:

$$
\left\{\begin{array}{l}
q_{1}(t)=\alpha_{1}-b\left(p_{1}(t)-\theta p_{2}(t)\right), \\
q_{2}(t)=\alpha_{2}-b\left(p_{2}(t)-\theta p_{1}(t)\right),
\end{array}\right.
$$

where $\alpha_{i}\left(\alpha_{i}>0\right)$ means the market capacity.

In the second and third stages, manufacturers collect used products from customers and remanufacture them. $p_{1}^{\prime}(t)$ and $p_{2}^{\prime}(t)$ are used to represent the price of used products in the period $t$ given by the manufacturer. We assume that based on the producer's responsibility extension system, the manufacturer only collects used products produced by himself, and meanwhile, all used products collected by the manufacturer will be remanufactured. In the process of recycling, customers also have price sensitivity which is captured by $f$. The recycling market capacity in the period $t$ 


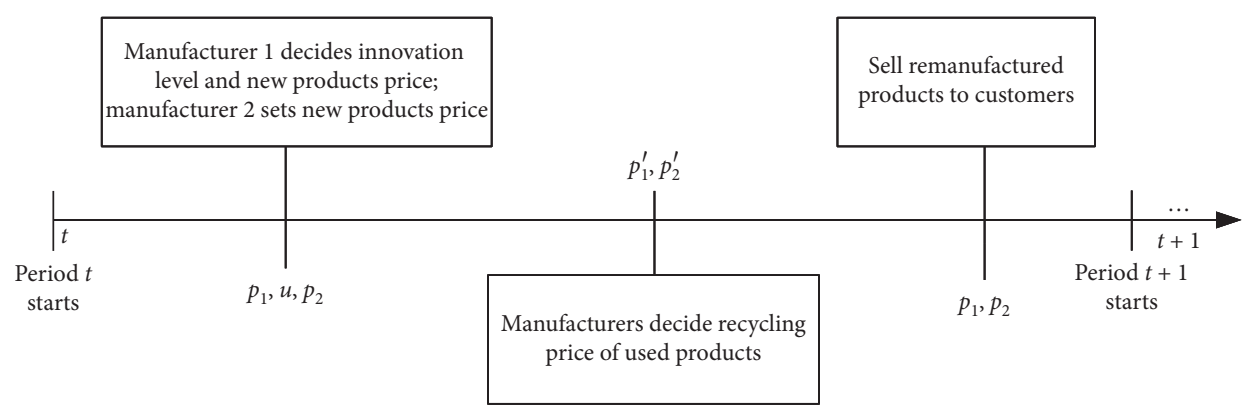

FIgURE 1: The timeline of decision-making.

is represented by $\lambda_{1} q_{1}(t)$ and $\lambda_{2} q_{2}(t)$, where $\lambda_{i}$ is the collection rate of used products and bounded by 0 and 1 . Then, the amount of recycled used products by each manufacturer in the period $t$ which is represented by $q_{1}^{\prime}(t)$ and $q_{2}^{\prime}(t)$ can be shown as follows:

$$
\begin{cases}q_{1}^{\prime}(t)=\lambda_{1} q_{1}(t)+f p_{1}^{\prime}(t), & f p_{1}^{\prime}(t)<q_{1}(t-1) \\ q_{2}^{\prime}(t)=\lambda_{2} q_{2}(t)+f p_{2}^{\prime}(t), & f p_{2}^{\prime}(t)<q_{2}(t-1)\end{cases}
$$

With environmental issues getting more and more serious, the government tries to figure out the dilemma of global warming and overexploitation of resources by inducing the manufacturers to produce green products. So, governmental subsidies, a kind of government financial intervention, are adopted when enterprises achieve the governmental goal [13]. In our model, the government encourages enterprises to carry on the activity of recycling. So, it gives a subsidy to enterprises according to the value of recycled used products, which is $\gamma p_{2}^{\prime}(t) q_{2}^{\prime}(t) . \gamma$ is the government subsidy rate for remanufactured products and is nonnegative. Responding to government requirements and improving competitiveness, the manufacturers take the responsibility of recycling and remanufacturing, and one of them invests in related greener technology to improve the product availability rate of recycled products, which can be expressed by $u$, and the manufacturer also saves some cost in the process of remanufacturing. The amount of investment can be expressed by $I=\beta u^{2}$, where the parameter $\beta$ is the investment efficiency; the bigger the investment efficiency is, the more cost the manufacturer will put into the investment. $I=\beta u^{2}$ can also be expressed by $u=\sqrt{I / \beta}$ which is consistent with the marginal diminishing effect. With the product availability rate of recycled products increasing, the manufacturer can save the cost $u c_{1}^{\prime}$. Then, the profits of manufacturers can be expressed as follows:

$$
\left\{\begin{array}{l}
\pi_{1}(t)=\left(p_{1}(t)-c_{1}\right)\left(q_{1}(t)-q_{1}^{\prime}(t)\right)+\left(p_{1}(t)-(1-u) c_{1}^{\prime}-p_{1}^{\prime}(t)\right) q_{1}^{\prime}(t)-\beta u^{2}+\gamma p_{1}^{\prime}(t) q_{1}^{\prime}(t) \\
\pi_{2}(t)=\left(p_{2}(t)-c_{2}\right)\left(q_{2}(t)-q_{2}^{\prime}(t)\right)+\left(p_{2}(t)-c_{2}^{\prime}-p_{2}^{\prime}(t)\right) q_{2}^{\prime}(t)+\gamma p_{2}^{\prime}(t) q_{2}^{\prime}(t)
\end{array}\right.
$$

where $c_{1}$ is the unit cost of production when new products are produced and $c_{1}^{\prime}$ represents the unit cost of production when remanufactured products are produced. There are some constraints: (1) $q_{i}^{\prime}<q_{i}, i=1,2$ : the number of recycled products cannot be larger than the number of new products manufactured in stage one. (2) $q_{i}^{\prime}, q_{i} \geq 0, i=1,2$ : the output is nonnegative.

Besides the assumptions we mentioned above, there are some other assumptions needed to be clarified. First of all, we ignore the costs of inventory holding, inventory shortage, transportation, and so on to simplify the model. Then, we assume that new products and remanufactured products have the same quality. Recycled products of the same quality can be sold again for the same price. For example, the gold ornament is recycled through channels and can be reprocessed into an ornament for sale. As long as the quality of the gold is the same, the price will be the same. Besides, we assume that the manufacturers in our model are bounded rational.

\section{Model Solving}

According to what we stated, there are three stages in our model where manufacturers produce new products and sell them to customers, and then, they collect the used products and remanufacture them. We divide the process into two pricing stages in which the new products are priced first and the used products can be priced then. So, we use the classic backward induction to solve this game model. Manufacturers decide their price of used products in the period $t$ to maximize their profit first; then based on imperfect information, manufacturers are bounded 
rational and decide their price of used products in the period $t+1$.
Substituting equations (1) and (2) into equation (3) and taking the partial derivative of $p_{1}^{\prime}(t)$ and $p_{2}^{\prime}(t)$, then we get the following:

$$
\left\{\begin{array}{l}
\frac{\partial \pi_{1}(t)}{\partial p_{1}^{\prime}(t)}=c_{1} f+c_{1}^{\prime} f(-1+u)+(-1+\gamma)\left(2 f p_{1}^{\prime}(t)+\left(\alpha_{1}-b p_{1}(t)+b \theta p_{2}(t)\right) \lambda_{1}\right) \\
\frac{\partial \pi_{2}(t)}{\partial p_{2}^{\prime}(t)}=c_{2} f-c_{2}^{\prime} f+(-1+\gamma)\left(2 f p_{2}^{\prime}(t)+\left(a_{2}-b p_{2}(t)+b \theta p_{1}(t)\right) \lambda_{2}\right)
\end{array}\right.
$$

We make $\left(\partial \pi_{1}(t) / \partial p_{1}^{\prime}(t)\right)=0$ and $\left(\partial \pi_{2}(t) / \partial p_{2}^{\prime}(t)\right)=0$; then, the result can be shown as follows:

$$
\left\{\begin{array}{l}
p_{1}^{\prime}(t)^{*}=\frac{f\left(c_{1}-c_{1}^{\prime}(1-u)\right)+\lambda_{1}(\gamma-1)\left(\alpha_{1}-b\left(p_{1}(t)-\theta p_{2}(t)\right)\right)}{2 f(1-\gamma)} \\
p_{2}^{\prime}(t)^{*}=\frac{f\left(c_{2}-c_{2}^{\prime}\right)+\lambda_{2}(\gamma-1)\left(\alpha_{2}-b\left(p_{2}(t)-\theta p_{1}(t)\right)\right)}{2 f(1-\gamma)}
\end{array}\right.
$$

Substituting equation (5) into equation (3), then the profit functions can be rewritten as follows:

$$
\left\{\begin{array}{l}
\pi_{1}=\left(p_{1}+\frac{1}{2} c_{1}\left(2-\lambda_{1}\right)\right)\left(-b p_{1}+b \theta p_{2}+\alpha_{1}\right)-u^{2} \beta+\frac{f c_{1}^{2}-2 f(1-u) c_{1} c_{1}^{\prime}}{4(1-\gamma)}+\frac{\left(f(-1+u) c_{1}^{\prime}+(-1+\gamma)\left(b p_{1}-b \theta p_{2}-\alpha_{1}\right) \lambda_{1}\right)^{2}}{4 f(1-\gamma)} \\
\pi_{2}=\left(b \theta p_{1}-b p_{2}+\alpha_{2}\right)\left(\frac{1}{2} \lambda_{2}\left(c_{2}-c_{2}^{\prime}\right)-\left(p_{2}-c_{2}\right)\right)+\frac{f\left(c_{2}-c_{2}^{\prime}\right)^{2}}{4(1-\gamma)}+\frac{(1-\gamma) \lambda_{2}^{2}}{4 f}\left(b \theta p_{1}-b p_{2}+\alpha_{2}\right)^{2} .
\end{array}\right.
$$

The marginal return of manufacturers is

$$
\left\{\begin{array}{l}
\frac{\partial \pi_{1}}{\partial u}=\frac{f c_{1}^{\prime}\left(c_{1}+(-1+u) c_{1}^{\prime}\right)}{2(1-\gamma)}-\frac{\lambda_{1} c_{1}^{\prime}}{2}\left(b p_{1}-b \theta p_{2}-\alpha_{1}\right)-2 u \beta \\
\frac{\partial \pi_{1}}{\partial p_{1}}=b\left(c_{1}-2 p_{1}+\theta p_{2}\right)+\alpha_{1}-\frac{1}{2} b\left(c_{1}+(-1+u) c_{1}^{\prime}\right) \lambda_{1}-\frac{b(-1+\gamma)\left(b p_{1}-b \theta p_{2}-\alpha_{1}\right) \lambda_{1}^{2}}{2 f} \\
\frac{\partial \pi_{2}}{\partial p_{2}}=b\left(c_{2}+\theta p_{1}-2 p_{2}\right)+\alpha_{2}+\frac{1}{2} b\left(-c_{2}+c_{2}^{\prime}\right) \lambda_{2}+\frac{b(-1+\gamma)\left(b \theta p_{1}-b p_{2}+\alpha_{2}\right) \lambda_{2}^{2}}{2 f}
\end{array}\right.
$$

In reality, limited to obtaining information, the enterprise cannot learn about the exact innovation output decisions that its rival makes and the decisions are not made by maximizing the profits [7]. Besides, in the long term, the decision process of the manufacturers is dynamic, and manufactures will adjust their decisions every stage. According to the assumptions we made earlier, manufacturers in our model are bounded rational. So, they make decisions in the period $t+1$ based on price and the marginal profit in the period $t$. The decision variable adjustment 
coefficient is introduced and the results of the repeated game in a long time can be shown as follows:

$$
\left\{\begin{array}{l}
u(t+1)=u(t)+w u(t) \frac{\partial \pi_{1}(t)}{\partial u(t)}, \\
p_{1}(t+1)=p_{1}(t)+v_{1} p_{1}(t) \frac{\partial \pi_{1}(t)}{\partial p_{1}(t)} \\
p_{2}(t+1)=p_{2}(t)+v_{2} p_{2}(t) \frac{\partial \pi_{2}(t)}{\partial p_{2}(t)} .
\end{array}\right.
$$

During the process of a repeated game, manufacturers adjust their pricing strategy on the basis of the marginal profit and pricing decision in the period $t$. When the marginal profit of a manufacturer in the period $t$ is positive, the same strategy would be adopted by the manufacturer in the next period $t+1$; on the other hand, when the marginal profit in the period $t$ is negative, the manufacturer would adjust his pricing strategy and recycled product availability rate decision. When a manufacturer adjusts pricing and investment decision in the period $t+1$, the whole system stability will be affected.

To get the equilibrium, we make $u(t+1)=u(t)$, $p_{1}(t+1)=p_{1}(t)$, and $p_{2}(t+1)=p_{2}(t)$. Then, we obtain eight points. But in our model, we just consider two manufacturers both carried on the competition. So, $u^{*}=0$, $p_{1}^{*}=0$, and $p_{2}^{*}=0$ are not taken into consideration. In the end, the equilibrium can be obtained as

$$
\left(u^{*}, p_{1}^{*}, p_{2}^{*}\right)
$$

where

$$
\begin{aligned}
u^{*}= & \left(f c _ { 1 } ^ { \prime } \left(f c_{1}^{\prime}\left(2 f\left(-4+\theta^{2}\right)+b(-1+\gamma)\left(-2+\theta^{2}\right) \lambda_{2}^{2}\right)-(-1+\gamma) \lambda_{1}\left(2 f\left(b \theta c_{2}+2 \alpha_{1}+\theta \alpha_{2}\right)+b f \theta\left(-c_{2}+c_{2}^{\prime}\right) \lambda_{2}\right.\right.\right. \\
& \left.+b(-1+\gamma)\left(\alpha_{1}+\theta \alpha_{2}\right) \lambda_{2}^{2}\right)+c_{1}\left(-2 f^{2}\left(-4+\theta^{2}\right)+b(-1+\gamma)\left(-2 f\left(-2+\theta^{2}\right) \lambda_{1}+\left(-f\left(-2+\theta^{2}\right)-b(-1+\gamma)\left(-1+\theta^{2}\right) \lambda_{1}\right) \lambda_{2}^{2}\right)\right) \\
& \cdot\left(f^{2} c_{1}^{\prime 2}\left(2 f\left(-4+\theta^{2}\right)+b(-1+\gamma)\left(-2+\theta^{2}\right) \lambda_{2}^{2}\right)+2 \beta(-1+\gamma)\left(4 f^{2}\left(-4+\theta^{2}\right)+b(-1+\gamma)\left(2 f\left(-2+\theta^{2}\right) \lambda_{2}^{2}\right.\right.\right. \\
& \left.\left.+\lambda_{1}^{2}\left(2 f\left(-2+\theta^{2}\right)+b(-1+\gamma)\left(-1+\theta^{2}\right) \lambda_{2}^{2}\right)\right)\right)^{-1}, \\
p_{1}^{*}= & -\left(\left(2 f\left(f\left(4 \beta(-1+\gamma)+f c_{1}^{\prime 2}\right)\left(2 \alpha_{1}+\theta \alpha_{2}\right)+4 b f \beta(-1+\gamma) c_{1}^{\prime} \lambda_{1}+2 b \beta(-1+\gamma)^{2}\left(2 \alpha_{1}+\theta \alpha_{2}\right) \lambda_{1}^{2}\right)\right.\right. \\
& -b f \theta c_{2}\left(f^{2} c_{1}^{\prime 2}+2 \beta(-1+\gamma)\left(2 f+b(-1+\gamma) \lambda_{1}^{2}\right)\right)\left(-2+\lambda_{2}\right)+b f \theta c_{2}^{\prime}\left(f^{2} c_{1}^{\prime 2}+2 \beta(-1+\gamma)\left(2 f+b(-1+\gamma) \lambda_{1}^{2}\right)\right) \lambda_{2} \\
& +b(-1+\gamma)\left(-2+\lambda_{2}\right)+b f \theta c_{2}^{\prime}\left(f^{2} c_{1}^{\prime 2}+2 \beta(-1+\gamma)\left(2 f+b(-1+\gamma) \lambda_{1}^{2}\right)\right) \lambda_{2}+b(-1+\gamma)\left(f\left(4 \beta(-1+\gamma)+f c_{1}^{\prime 2}\right)\left(\alpha_{1}+\theta \alpha_{2}\right)\right. \\
& \left.\left.+2 b f \beta(-1+\gamma) c_{1}^{\prime} \lambda_{1}+2 b \beta(-1+\gamma)^{2}\left(\alpha_{1}+\theta \alpha_{2}\right) \lambda_{1}^{2}\right) \lambda_{2}^{2}+b f c_{1}\left(f c_{1}^{\prime 2}-2 \beta(-1+\gamma)\left(-2+\lambda_{1}\right)\right)\left(4 f+b(-1+\gamma) \lambda_{2}^{2}\right)\right) \\
& +\left(b \left(2 f\left(f\left(-4+\theta^{2}\right)\left(4 \beta(-1+\gamma)+f c_{1}^{\prime 2}\right)+2 b \beta(-1+\gamma)^{2}\left(-2+\theta^{2}\right) \lambda_{1}^{2}\right)\right.\right. \\
& \left.\left.\left.+b(-1+\gamma)\left(f\left(-2+\theta^{2}\right)\left(4 \beta(-1+\gamma)+f c_{1}^{\prime 2}\right)+2 b \beta(-1+\gamma)^{2}\left(-1+\theta^{2}\right) \lambda_{1}^{2}\right) \lambda_{2}^{2}\right)\right)\right)^{-1}, \\
& \left.\left.\left.+b(-1+\gamma)\left(f\left(-2+\theta^{2}\right)\left(4 \beta(-1+\gamma)+f c_{1}^{\prime 2}\right)+2 b \beta(-1+\gamma)^{2}\left(-1+\theta^{2}\right) \lambda_{1}^{2}\right) \lambda_{2}^{2}\right)\right)\right)^{-1} . \\
p_{2}^{*}= & -\left(\left(2 f\left(f\left(4 \beta(-1+\gamma)+f c_{1}^{\prime 2}\right)\left(\theta \alpha_{1}+2 \alpha_{2}\right)+2 b f \beta(-1+\gamma) \theta c_{1}^{\prime} \lambda_{1}+2 b \beta(-1+\gamma)^{2}\left(\theta \alpha_{1}+\alpha_{2}\right) \lambda_{1}^{2}\right)\right.\right. \\
& +2 b f c_{2}\left(f^{2} c_{1}^{\prime 2}+\beta(-1+\gamma)\left(4 f+b(-1+\gamma) \lambda_{1}^{2}\right)\right)\left(-2+\lambda_{2}\right)+2 b f c_{2}^{\prime}\left(f^{2} c_{1}^{\prime 2}+\beta(-1+\gamma)\left(4 f+b(-1+\gamma) \lambda_{1}^{2}\right)\right) \lambda_{2} \\
& +b(-1+\gamma)\left(f\left(4 \beta(-1+\gamma)+f c_{1}^{\prime 2}\right)\left(\theta \alpha_{1}+2 \alpha_{2}\right)+2 b f \beta(-1+\gamma) \theta c_{1}^{\prime} \lambda_{1}+2 b \beta(-1+\gamma)^{2}\left(\theta \alpha_{1}+\alpha_{2}\right) \lambda_{1}^{2}\right) \lambda_{2}^{2} \\
& \left(b\left(f\left(-4+\theta^{2}\right)\left(4 \beta(-1+\gamma)+f c_{1}^{\prime 2}\right)+2 b \beta(-1+\gamma)^{2}\left(-2+\theta^{2}\right) \lambda_{1}^{2}\right)\right. \\
& \left.\left.+b\left(-2+\lambda_{1}\right)\right)\left(2 f+b(-1+\gamma) \lambda_{2}^{2}\right)\right) \\
& +b(10)
\end{aligned}
$$


Based on the result, we can obtain the Jacobian matrix of this model as follows:

$$
\begin{aligned}
J & =\left(\begin{array}{ccc}
j_{11} & -\frac{1}{2} b u w c_{1}^{\prime} \lambda_{1} & \frac{1}{2} b u w \theta c_{1}^{\prime} \lambda_{1} \\
-\frac{1}{2} b c_{1}^{\prime} p_{1} v_{1} \lambda_{1} & j_{22} & \frac{b \theta p_{1} v_{1}\left(2 f+b(-1+\gamma) \lambda_{1}^{2}\right)}{2 f} \\
0 & \frac{b \theta p_{2} v_{2}\left(2 f+b(-1+\gamma) \lambda_{2}^{2}\right)}{2 f} & j_{33}
\end{array}\right), \\
j_{11} & =1-4 u w \beta+\frac{w c_{1}^{\prime}\left(-f c_{1}+(f-2 f u) c_{1}^{\prime}-(-1+\gamma)\left(b p_{1}-b \theta p_{2}-\alpha_{1}\right) \lambda_{1}\right)}{2(-1+\gamma)}, \\
j_{22} & =1+\frac{1}{2} v_{1}\left(2\left(b\left(c_{1}-4 p_{1}+\theta p_{2}\right)+\alpha_{1}\right)-b\left(c_{1}+(-1+u) c_{1}^{\prime}\right) \lambda_{1}\right)-\frac{b v_{1} \lambda_{1}^{2}}{2 f}(1-\gamma)\left(2 b p_{1}-b \theta p_{2}-\alpha_{1}\right), \\
j_{33}= & 1+v_{2}\left(b\left(c_{2}+\theta p_{1}-4 p_{2}\right)+\alpha_{2}\right)-\frac{b \lambda_{2} v_{2}}{2}\left(c_{2}-c_{2}^{\prime}\right)-\frac{v_{2}}{2 f}\left(b(1-\gamma)\left(b \theta p_{1}-2 b p_{2}+\alpha_{2}\right) \lambda_{2}^{2}\right) .
\end{aligned}
$$

From the Jacobian matrix of equation (9), we can find the characteristic equation of the matrix. So, we can obtain the characteristic equation of $J$ as follows:

$$
\begin{aligned}
f(\lambda)= & \lambda^{3}+z_{2} \lambda^{2}+z_{1} \lambda+z_{0}, \\
z_{2}= & -\left(j_{11}+j_{22}+j_{33}\right), \\
z_{1}= & \frac{b^{2} p_{1} v_{1}\left(-f^{2} u w c_{1}^{\prime 2} \lambda_{1}^{2}+\theta^{2} p_{2} v_{2}\left(2 f+b(-1+\gamma) \lambda_{1}^{2}\right)\left(-2 f-b(-1+\gamma) \lambda_{2}^{2}\right)\right)}{4 f^{2}}+j_{22} j_{33}+j_{11}\left(j_{22}+j_{33}\right), \\
z_{0}= & -j_{11} j_{22} j_{33}+\frac{j_{11}}{4 f^{2}}\left(b^{2} \theta^{2} p_{1} p_{2} v_{1} v_{2}\left(2 f-b(1-\gamma) \lambda_{1}^{2}\right)\left(2 f-b(1-\gamma) \lambda_{2}^{2}\right)\right) \\
& +\frac{1}{8 f^{2}}\left(b^{2} f u w c_{1}^{\prime 2} p_{1} v_{1} \lambda_{1}^{2}\left(2 f j_{33}+b \theta^{2} p_{2} v_{2}\left(2 f-b(1-\gamma) \lambda_{2}^{2}\right)\right)\right) .
\end{aligned}
$$

The stability conditions can be shown as follows, based on the Jury stability criterion [34] and equation (10):

$$
\left\{\begin{array}{l}
f(1)=1+z_{2}+z_{1}+z_{0}>0, \\
f(-1)=-1+z_{2}-z_{1}+z_{0}<0, \\
\left|z_{0}\right|<1 \\
\left|z_{0}^{2}-1\right|>\left|z_{0} z_{1}-z_{2}\right| .
\end{array}\right.
$$

\section{Numerical Simulation}

In Sections 2 and 3, we build and figure out the model. Considering the reality, we assume that manufacturers are bound rational because of limited information and they make decisions on the basis of the marginal profit and pricing decision in the period $t$. They carry on repeated games in a long time. In every stage, the manufacturer constantly adjusts the pricing strategy to get closer to the optimal price of profit maximization. As the results shown in Figure 1, when the speed of price adjustment is too high, the system will become unstable and enter the chaotic state. To understand the process of dynamic change accurately, we do numerical simulations, in which we set $\alpha_{1}=10, \alpha_{2}=8$, $b=1, \theta=0.6, \lambda_{1}=0.7, \lambda_{2}=0.6, f=2, c_{1}=2, c_{2}=1.5$, $c_{1}^{\prime}=0.4, \quad c_{2}^{\prime}=0.4, \quad \beta=10, \quad \gamma=0.5, \quad w=1, \quad v_{1}=0.1$, and $v_{2}=0.1$. And then, we can get the equilibrium point $\left(u^{*}, p_{1}^{*}, p_{2}^{*}\right)=(0.11,7.53,6.71)$. 
5.1. Stability Analysis. There are lots of parameters in the equilibrium of our model and it is difficult to analyze the model directly. So, we verify the stability of this model by doing numerical simulation according to the actual situation. The discrete triangle in Figure 2 is also part of the stability region. Then, the stable region about $w, v_{1}$, and $v_{2}$ is shown in Figure 2:

5.2. Influence of the Speed of Adjustment on the Stability of the System. In Figures 3-5, the bifurcation diagrams and largest Lyapunov exponent describe the change of $u, p_{1}$, and $p_{2}$ with their adjustment parameters. As shown in Figures 3-5, with $v_{1}$ increasing, the status of the system keeps stable at the beginning; then, it becomes bifurcation and ended in chaos. In a stable status, $p_{1}$ from manufacturer 1 is higher than $p_{2}$ from manufacturer 2 . When the value of $w, v_{1}$, and $v_{2}$ exceeds the critical points of bifurcation diagram, $u, p_{1}$, and $p_{2}$ bifurcate and then enter a chaotic state.

The largest Lyapunov exponent presents the system's state. When the largest Lyapunov exponent is smaller than zero, the manufacturers' decision system is stable. When the largest Lyapunov exponent is equal to zero, bifurcation happens. When the largest Lyapunov exponent is bigger than zero, the manufacturers' decision system enters chaos. When the values of $w, v_{1}$, and $v_{2}$ are small, the largest Lyapunov exponent is smaller than zero, which means that the system is stable. When the largest Lyapunov exponent is equal to zero first, bifurcation happens in the system. With $w, v_{1}$, and $v_{2}$ increasing continuously, there are some dots above the $X$-axis; that is, the largest Lyapunov exponent is bigger than zero.

As $w, v_{1}$, and $v_{2}$ change, the profits of the two manufacturers will also fluctuate. In Figures 6-8, we further explore the impact of $w, v_{1}$, and $v_{2}$ on profits.

From Figures 6-8, we can draw a conclusion that the profits of both manufacturers fluctuate with the expansion of the three parameters. This result also shows that excessive adjustment will lead to vicious competition in the market and result in instability. Among them, $w$ has the least impact on profits, while $v_{1}$ has the greatest impact on profits.

\subsection{Influence of the Investment and the Government Subsidy} on the Stability of the System. We further analyze the effect of the manufacturer's investment on the stable region of the system. In our work, one of the manufacturers invests in green innovation to improve the product availability rate of recycled products, which is captured by $u$. We range $u$ from 0 to 1 and obtain the $3 \mathrm{D}$ stable region with a change of $v_{1}, v_{2}$, and $u$ which is shown in Figure 9. By observing Figure 9, we can find that whatever $u$ is, the stable region stays the same all the time. That is, the product availability rate of recycled products has no effect on the stable region of the system.

Then, we analyze the effect of the government subsidy on the stability of the system. In our model, the government gives a subsidy to the enterprise on the basis of the value of recycled used products and the amount of subsidy is $\gamma p_{2}^{\prime}(t) q_{2}^{\prime}(t)$. We change $\gamma$ from 0 to 1 and get a stable region with a change of $v_{1}, v_{2}$, and $\gamma$. By observing Figure 10, we can

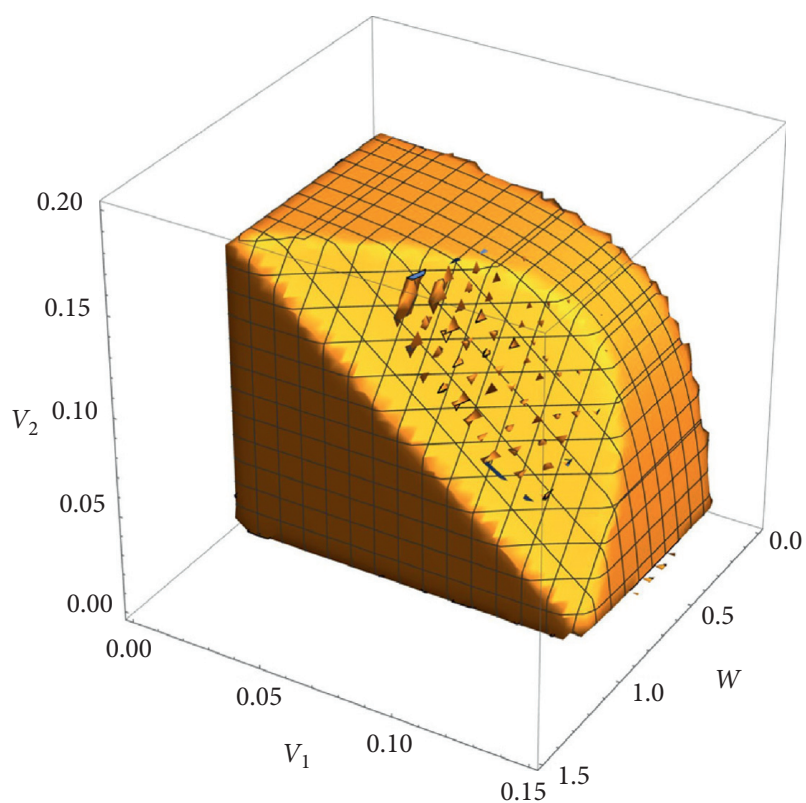

FIgURE 2: The stable region with a change of $w, v_{1}$, and $v_{2}$.

draw the conclusion that with $\gamma$ increasing, the area of stable region decreases gradually. To make the result clear, we set $\gamma=0, \gamma=0.3, \gamma=0.5, \gamma=0.7$, and $\gamma=0.9$ and get the stable region with a change of $v_{1}$ and $v_{2}$ which can be seen in Figure 10.

In Figure 11, the red-border area, the blue-border area, the green-border area, the purple-border area, and the blackborder area are obtained when we set $\gamma=0, \gamma=0.3, \gamma=0.5$, $\gamma=0.7$, and $\gamma=0.9$, respectively. It is clear that the bigger the $\gamma$ is, the smaller the area of the stable region is, which is consistent with the result we get from Figure 11. Based on this result, it can also be concluded that the government needs to set an appropriate level of subsidies to keep the stability of the system.

5.4. Effect of Parameters on the Nonlinear Dynamic Game System. First of all, we focus on the impact of the investment and the government subsidy on the system. We set $\alpha_{1}=10$, $\alpha_{2}=8, b=1, \theta=0.6, \lambda_{1}=0.7, \lambda_{2}=0.6, f=2, c_{1}=2$, $c_{2}=1.5, c_{1}^{\prime}=0.4, c_{2}^{\prime}=0.4$, and $\beta=10$ and illustrate how the price, demand, recycling price, recycling quantity, and profit go with the investment and government subsidy on the equilibrium point. The price $p_{1}$ with a change of $u$ is shown in Figure 12.

Figures 13-16 reveal the impact of the investment and government subsidy on manufacturer 1 . We find that the effect of the investment on manufacturer 1 is linear. With the increase of the investment, the price of product 1 drops slightly. By contrast, the demand, recycling price, and recycling quantity increase in this process. And the profit increases first but then decreases after reaching the maximum value. Based on those facts, we can draw the conclusion that certain investment has a positive force for product selling and recycling and the profit. However, too much investment will harm the profit of the manufacturer. 


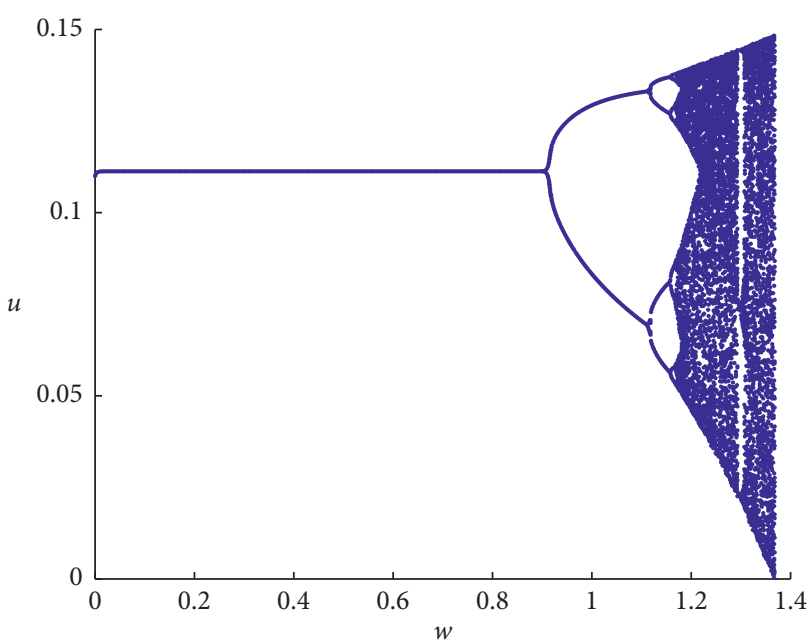

(a)

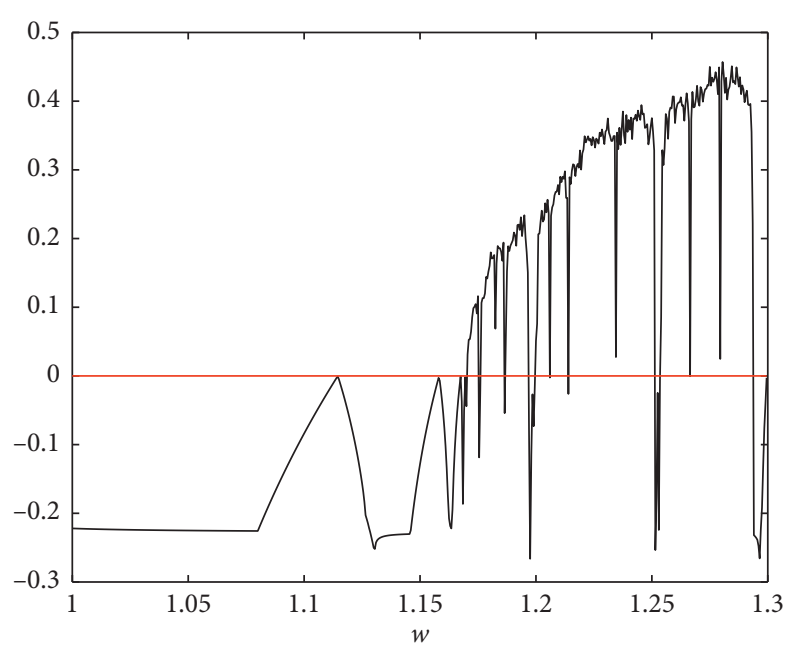

(b)

Figure 3: Bifurcation diagram and largest Lyapunov exponent of $u$ w.r.t. $w$.

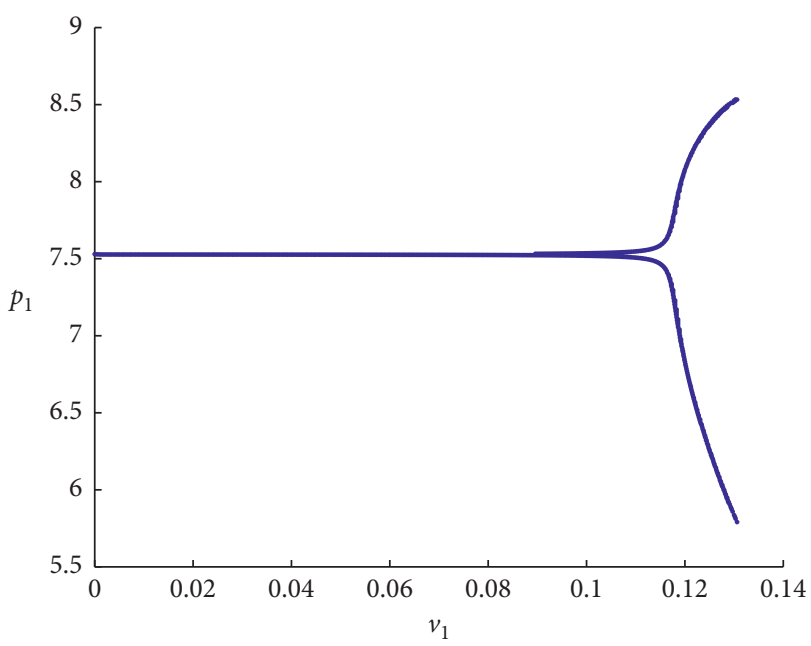

(a)

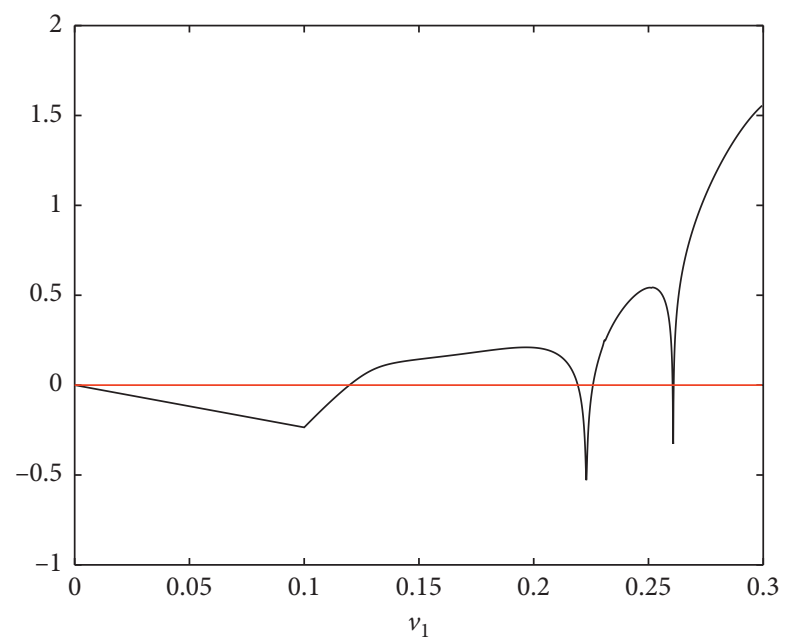

(b)

Figure 4: Bifurcation diagram and the largest Lyapunov exponent of $p_{1}$ w.r.t. $v_{1}$.

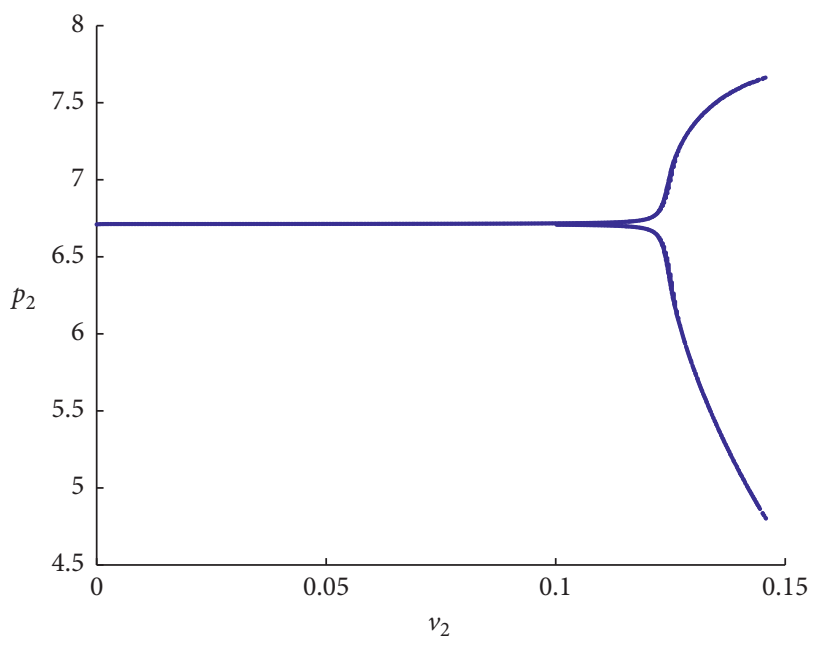

(a)

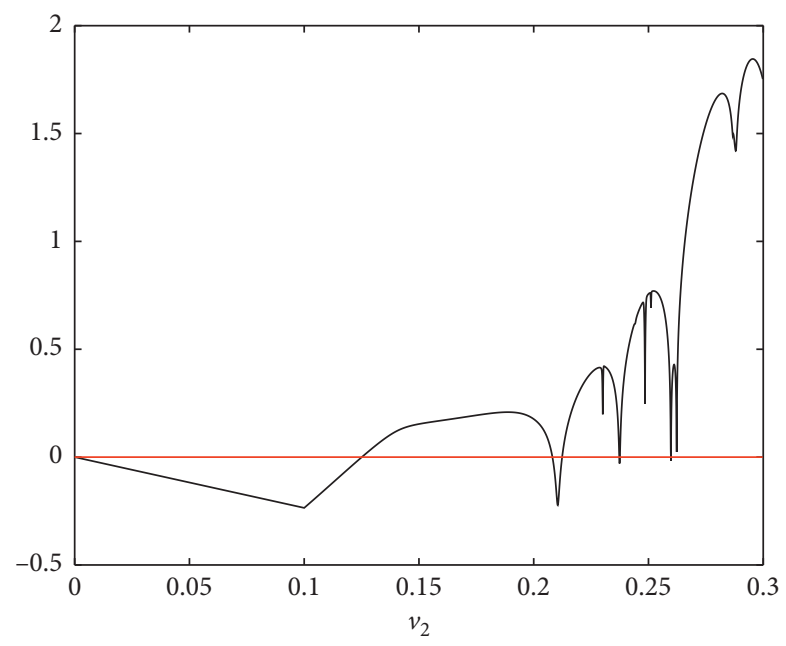

(b)

FIgURE 5: Bifurcation diagram and the largest Lyapunov exponent of $p_{2}$ w.r.t. $v_{2}$. 


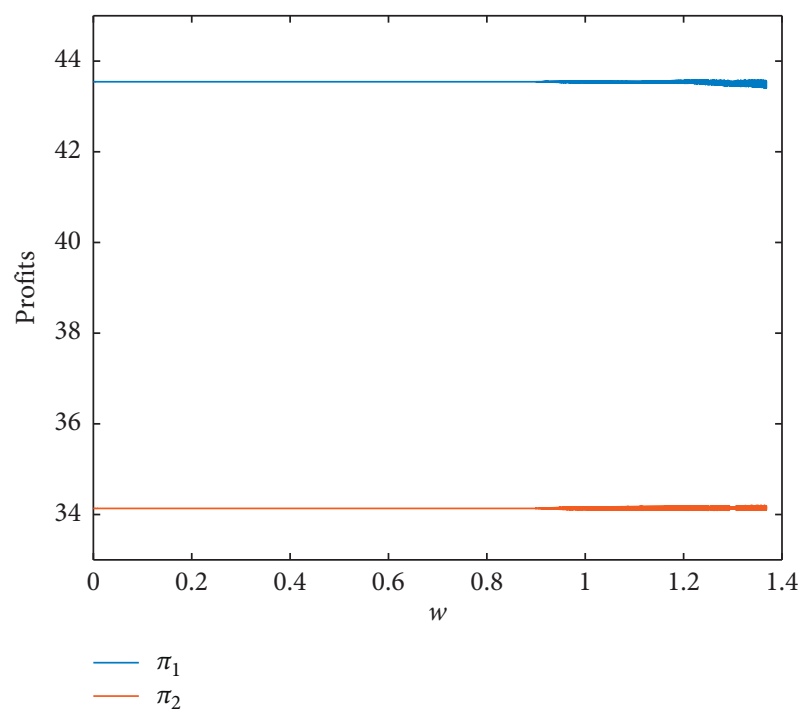

FIgURE 6: The profits of the two manufacturers with a change of $w$.

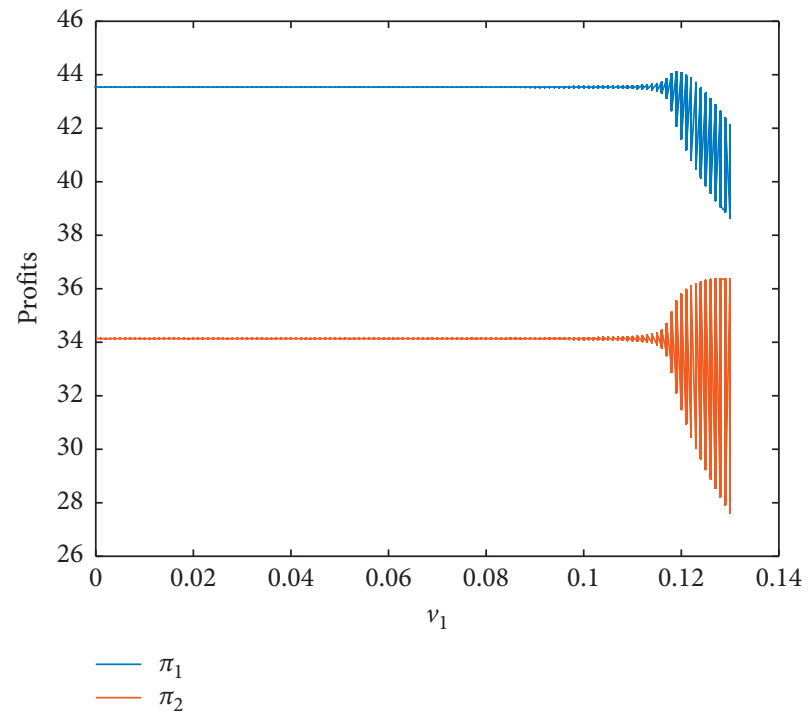

FIGURE 7: The profits of the two manufacturers with a change of $v_{1}$.

Compared to the investment, the government subsidy has a contrary impact on the price and the demand. But the government subsidy promotes the recycling price and recycling quantity similar to the way the investment does, but it is not linear. And the government subsidy undoubtedly raises the profit of manufacturer 1 .

We further analyze the effect of investment of manufacturer 1 and governmental subsidy on the pricing decision and profit of manufacturer 2. The result can be seen in Figures 17-21. With the product availability rate of recycled products increasing, the price, the demand, and the profit of manufacturer 2 decrease slightly. In our model, manufacturer 1 invests in green innovation to improve the product availability rate of recycled products which leads manufacturer 1 to have an advantage when competing with manufacturer 2. Accordingly, manufacturer 2 is at a disadvantage in the competition. However, with the increase of

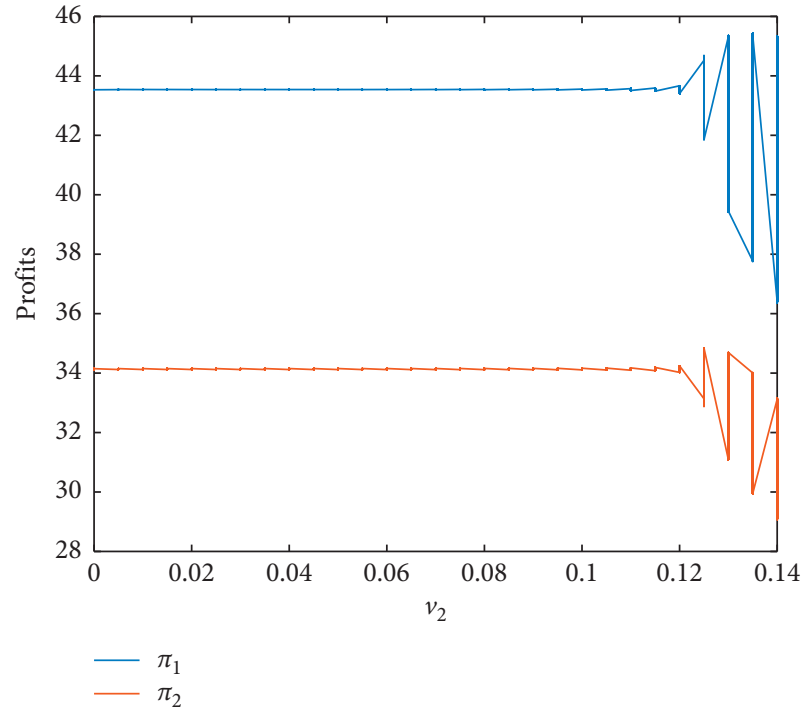

FIgURE 8: The profits of the two manufacturers with a change of $v_{2}$.

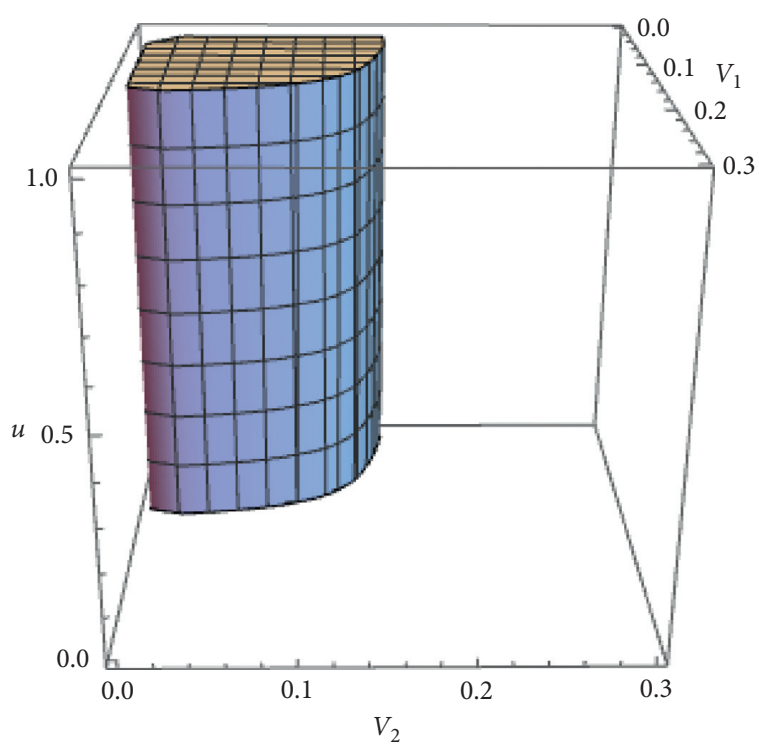

Figure 9: The 3D stable region with a change of $v_{1}, v_{2}$, and $u$.

the investment, both the price and the amount of recycling used products remain unchanged. There is no competition between manufacturers in the recycling market, since we assume that the manufacturer only collects used products produced by himself. Compared to the investment, the government subsidy has a positive impact on the price and has a negative impact on demand. But the government subsidy promotes the recycling price and recycling quantity similar to the result we get earlier. And the government subsidy undoubtedly raises the profit of manufacturer 2 .

Next, we will explore the impact of the collection rate on the profits of both manufacturers.

From Figure 22, we can see that when the value of $\lambda_{2}$ is lower and the value of $\lambda_{1}$ is higher, the profit of manufacturer 1 is higher. Conversely, when $\lambda_{2}$ is higher and $\lambda_{1}$ is lower, manufacturer 2's profit is higher. This shows that a 


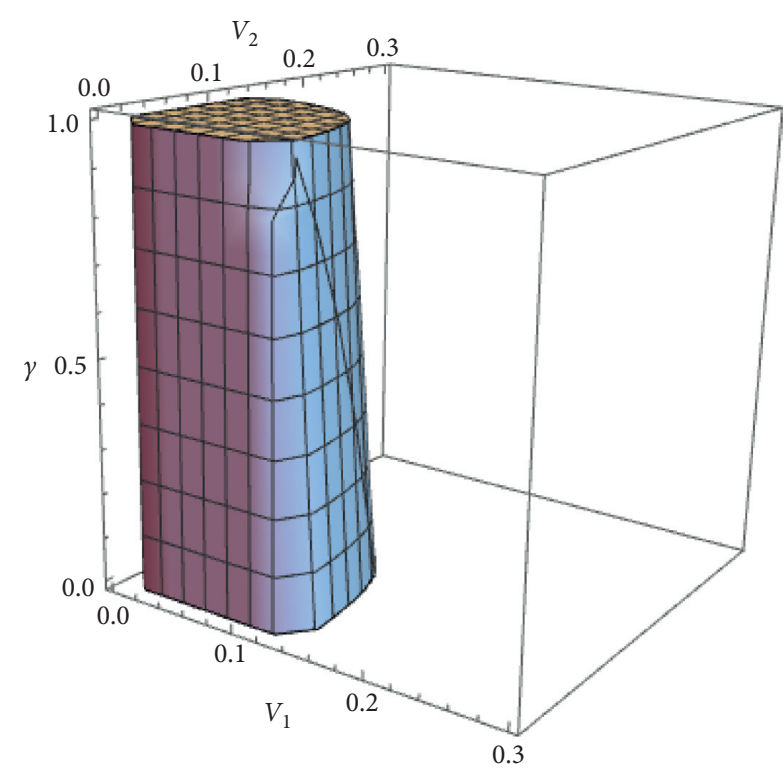

Figure 10: The 3D stable region with a change of $v_{1}, v_{2}$, and $\gamma$.

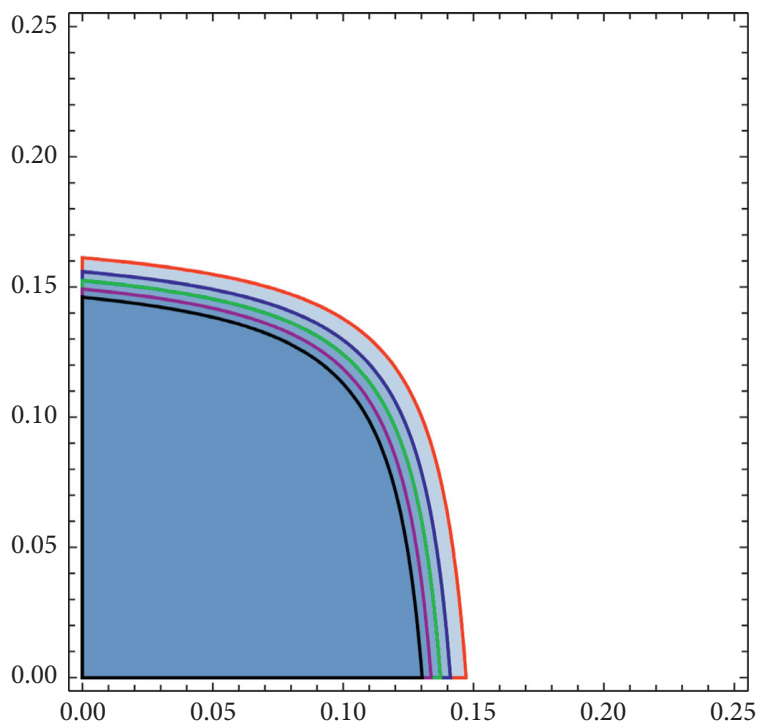

FIgURE 11: The stable region with a change of $v_{1}$ and $v_{2}$.

high collection rate is connected with high profits. This is also in line with reality.

In the end, we focus on the impact of the investment, the price sensitivity, and the degree of substitution between two kinds of similar products on the system.

From Figures 23 and 24, we can draw the following conclusions. Among the three decision-making factors, the product substitution rate has the most significant impact on the manufacturer's profit, followed by the price sensitivity, and the impact of investment is the smallest. Therefore, manufacturers should first pay attention to product innovation and change the substitution rate of products. In addition, manufacturers should set reasonable selling prices to meet consumers' demand, and finally, manufacturers should invest more in products if they can.

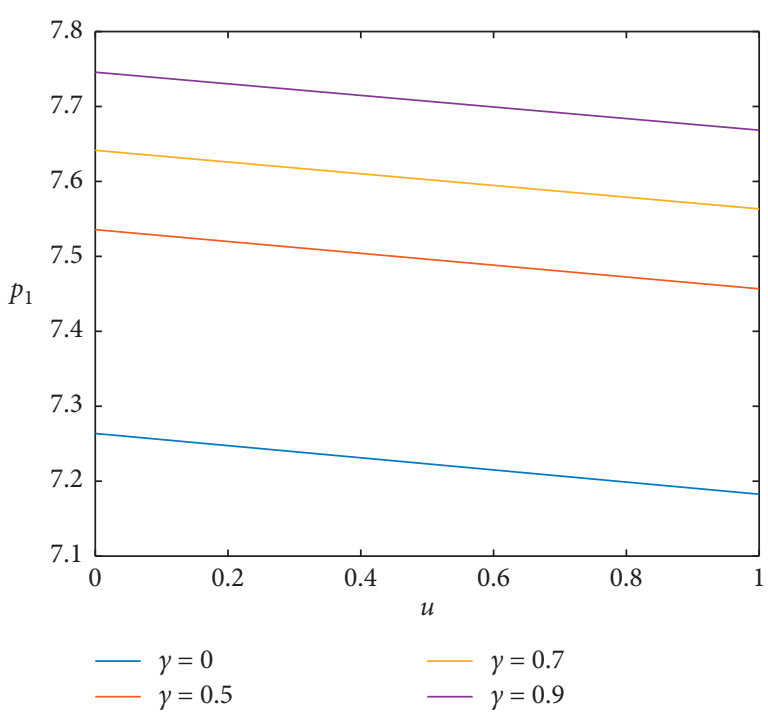

FIgURE 12: The price $p_{1}$ with a change of $u$.

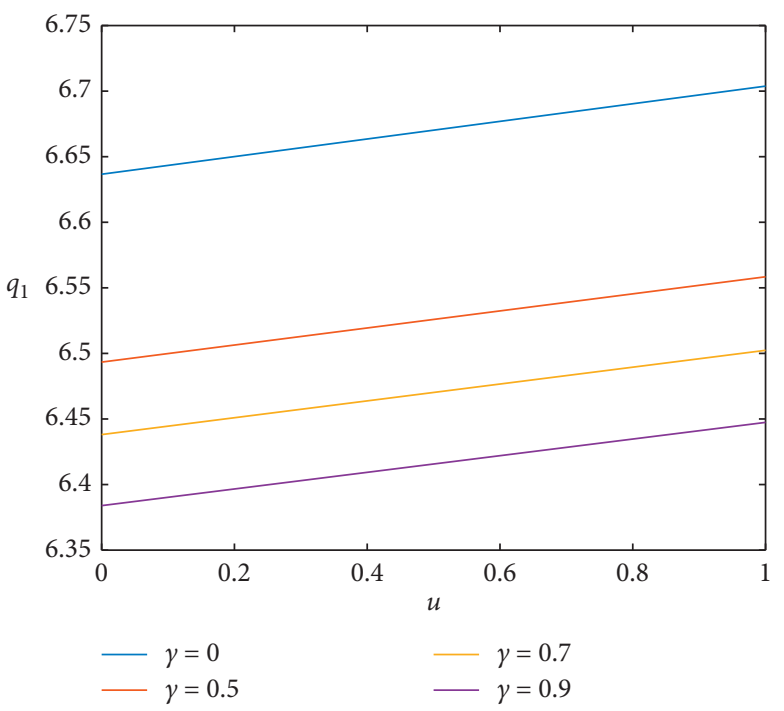

Figure 13: The demand $q_{1}$ with a change of $u$.

5.5. Change of Pareto Solutions on the Dynamic Game System. In this section, we focus on the effect of the adjustment rates of the two manufacturers on the Pareto solutions.

From Figure 25, we can see that as the period increases, the range of Pareto solutions gradually expands. When the dynamic game reaches a certain period, the range of Pareto solution tends to be stable. When $v_{1}<0.18$ and $v_{2}<0.2$, there are inferior solutions to the system. Therefore, with the development of the dynamic game, the two manufacturers should increase their adjustment rate to avoid the generation of the inferior solution, so as to realize the Pareto optimization of the whole system.

\section{Chaos Control}

As the result has shown earlier, once the speed of adjustment of the participants in the market exceeds a reasonable 


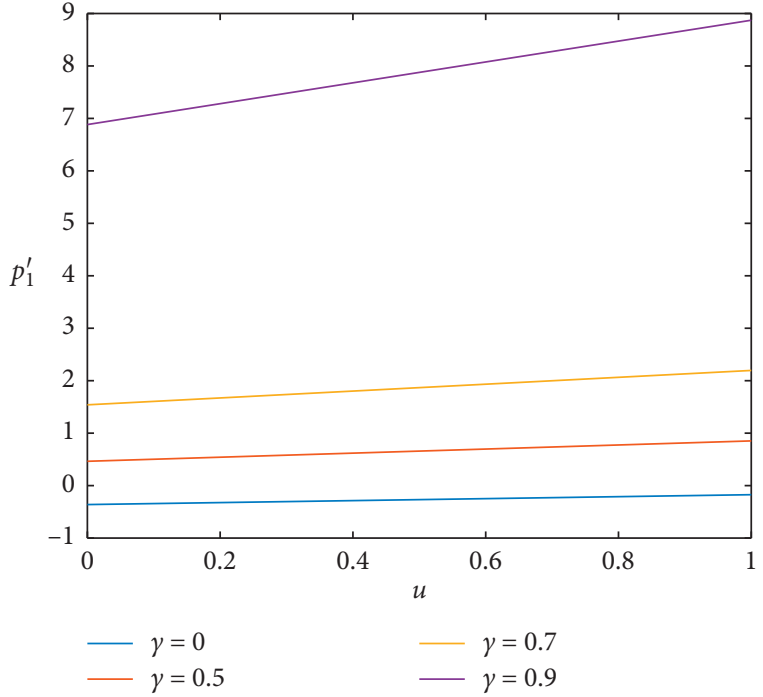

FIGURE 14: The recycling price $p_{1}^{\prime}$ with a change of $u$.

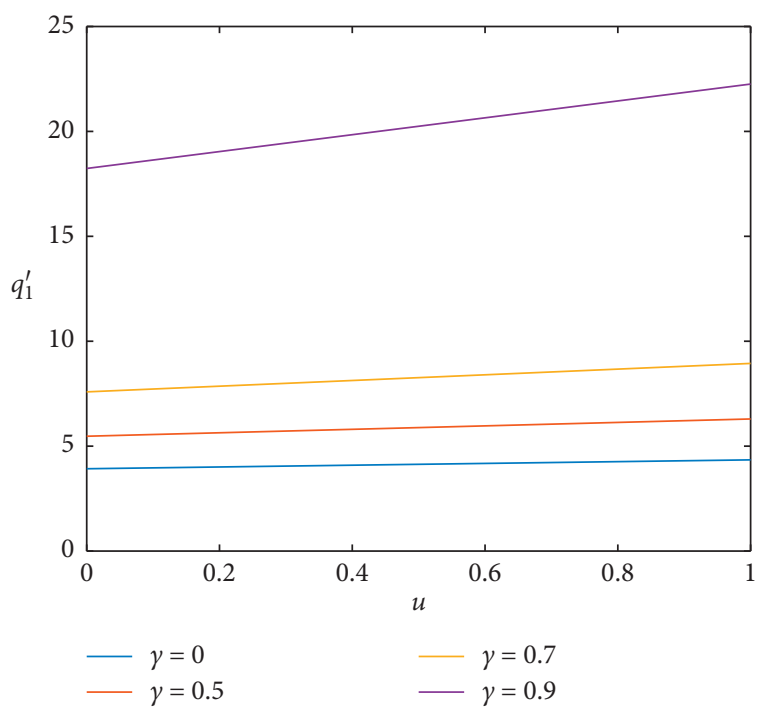

FIGURE 15: The recycling quantity $q_{1}^{\prime}$ with a change of $u$.

threshold, the market would fall into a state of complex chaos, which will cause disordered fluctuations in the price decision and the amount of recycling used products. As a result, manufacturers are unable to make the optimal response in the current period; thus, their profits will also have violent fluctuations. Considering this result from the chaos, it is necessary to control chaos effectively to ensure the stability of market competition and benefit the whole system. In this section, based on the characteristics of the whole decision-making process, we introduce the method by adjusting the decision method to control the chaos. Thus, the delay control method and the parameter adjustment control method are considered.

Firstly, control analysis is carried out through parameter adjustment control. Managers can control chaotic behavior

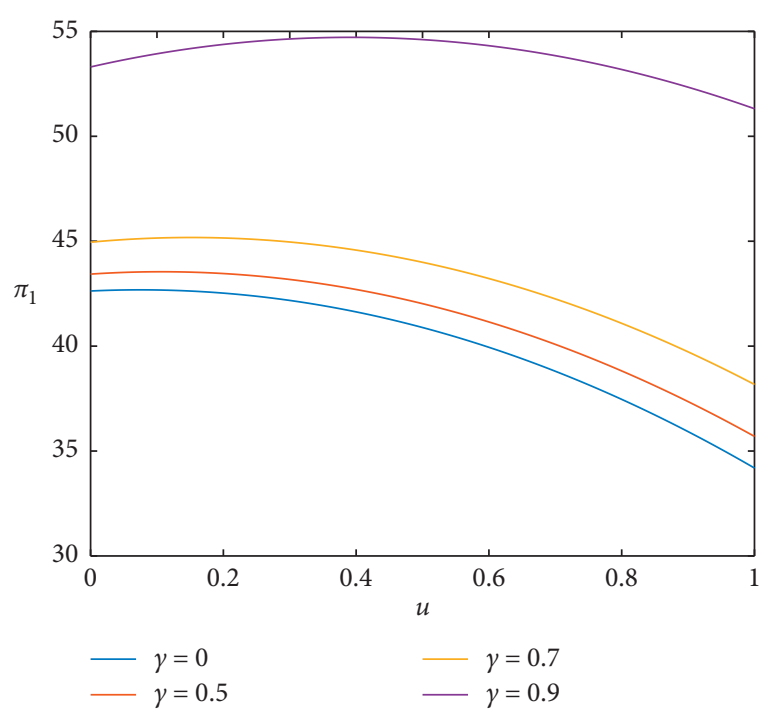

FIGURE 16: The profit $\pi_{1}$ with a change of $u$.

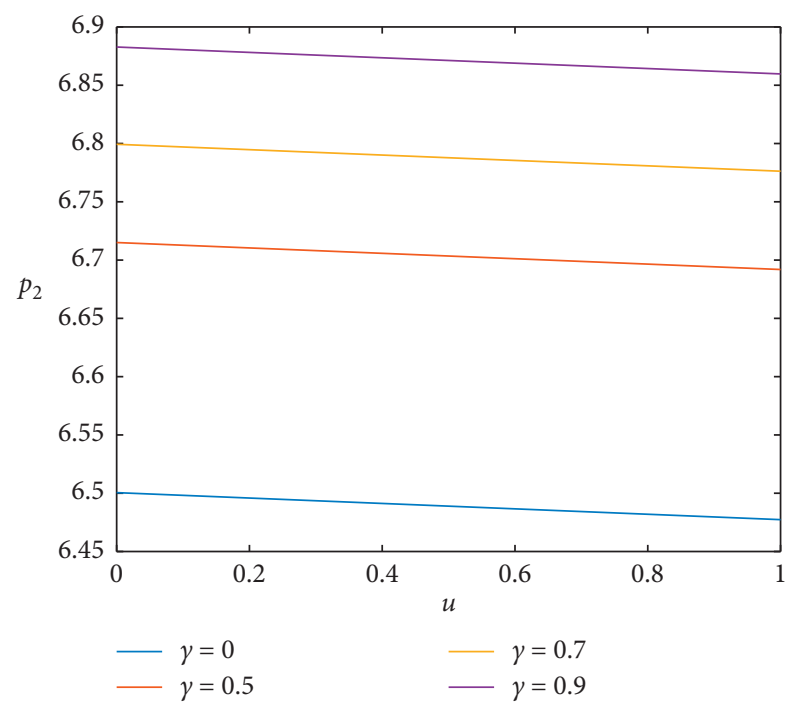

FIgURE 17: The price $p_{2}$ with a change of $u$.

by introducing a control parameter $g$. Wang [35] realized a chaos control by setting the control parameter as $g$. Under parameter adjustment control, the simultaneous decision system can be expressed as

$$
\left\{\begin{array}{l}
p_{1}(t+1)=(1-g)\left(p_{1}(t)+v_{1} p_{1}(t) \frac{\partial \Pi_{1}(t)}{\partial p_{1}(t)}\right)+g p_{1}(t), \\
p_{2}(t+1)=(1-g)\left(p_{2}(t)+v_{2} p_{2}(t) \frac{\partial \Pi_{2}(t)}{\partial p_{2}(t)}\right)+g p_{2}(t) .
\end{array}\right.
$$

Then, we use the delay control method to control chaos. The core idea of the delay control method is to use feedback to the system after a time delay (2016). That is, we take part of the information that is the output signal of the system into consideration. When making a decision next period, we 


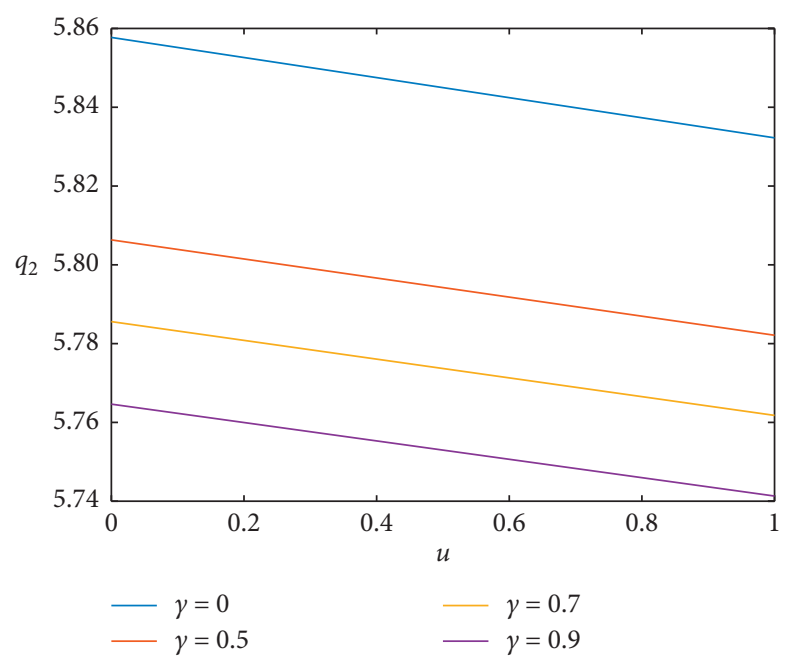

Figure 18: The demand $q_{2}$ with a change of $u$.

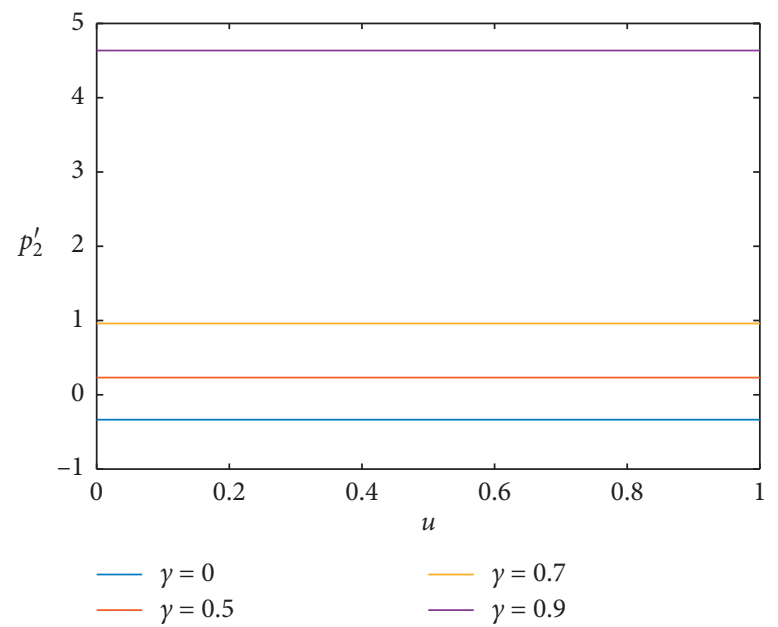

FIGURE 19: The recycling price $p_{2}^{\prime}$ with a change of $u$.

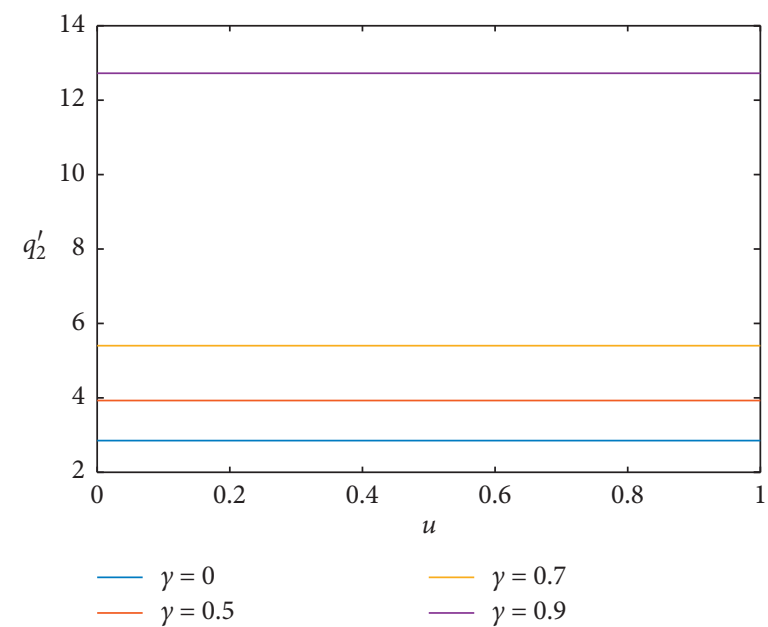

FIgURE 20: The recycling quantity $q_{2}^{\prime}$ with a change of $u$. 


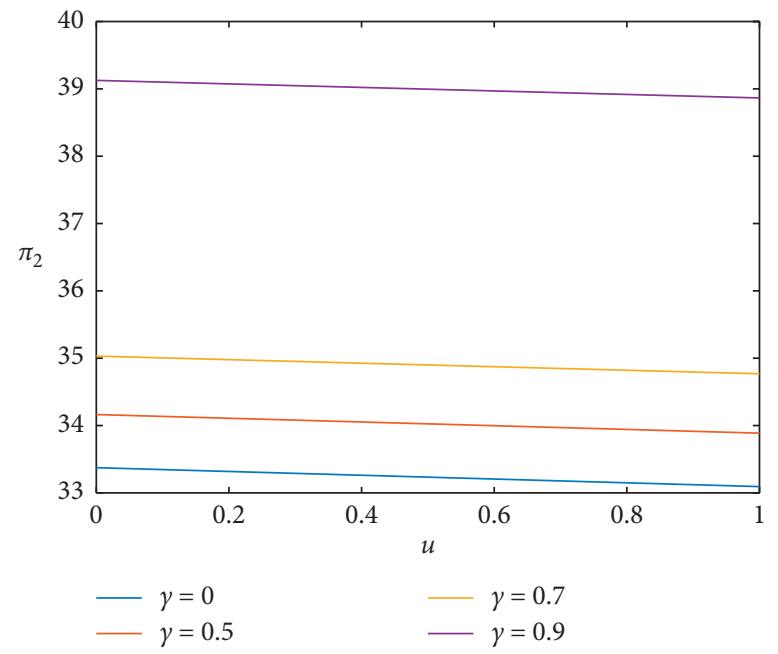

Figure 21: The profit $\pi_{2}$ with a change of $u$.

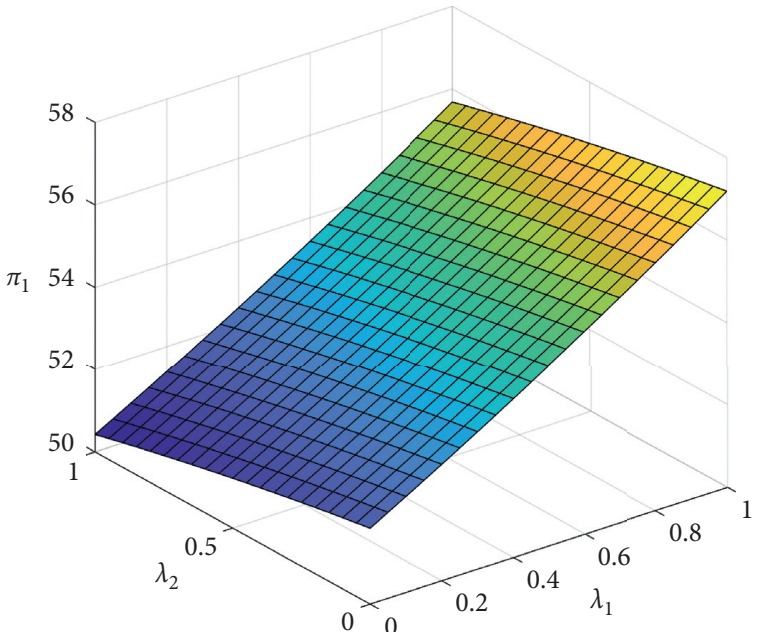

(a)

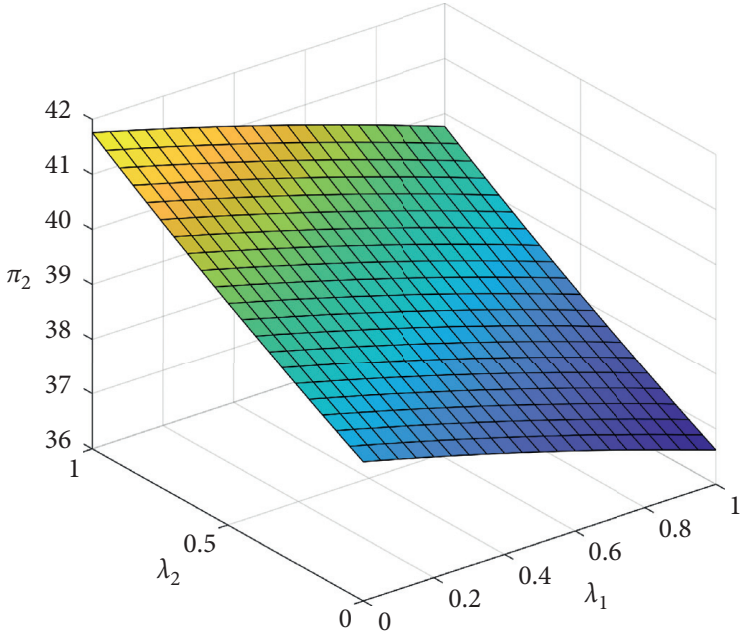

(b)

Figure 22: The profits with a change of $\lambda_{1}$ and $\lambda_{2}$.

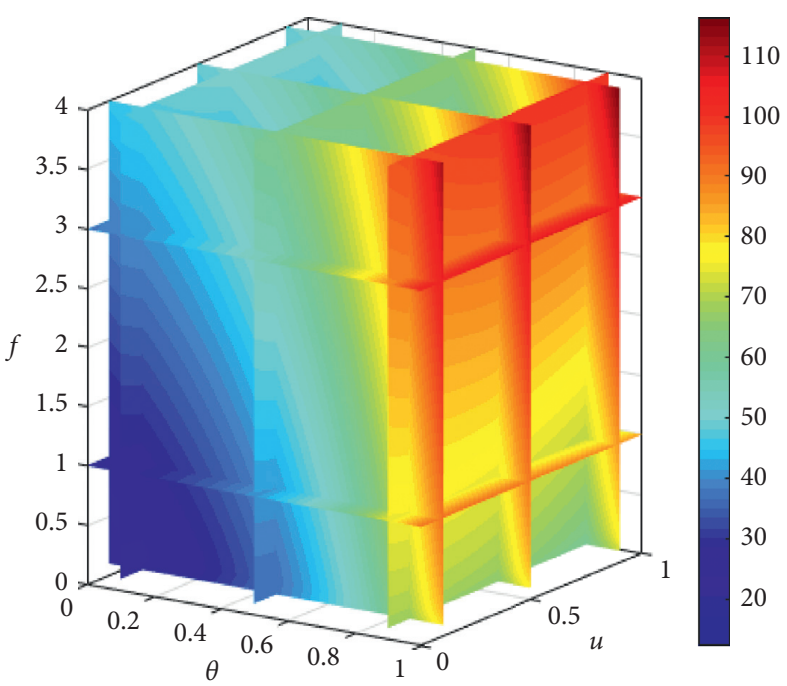

(a)

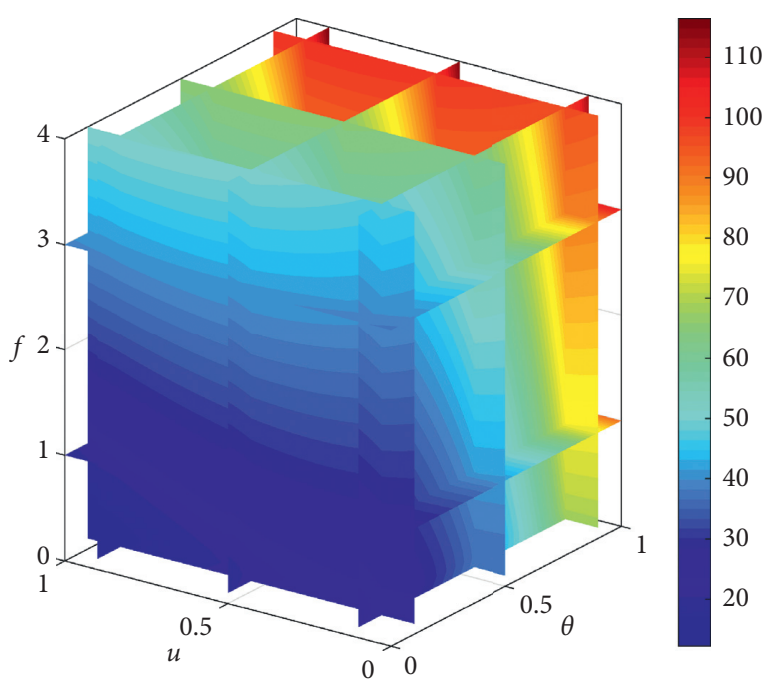

(b)

Figure 23: The effect of $u, \theta$, and $f$ on the profit of manufacturer 1. (a) Back. (b) Front. 


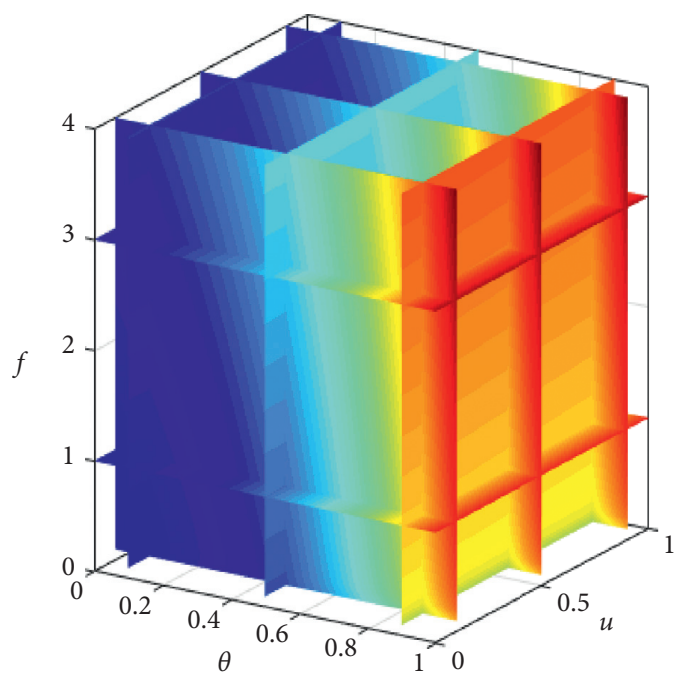

(a)

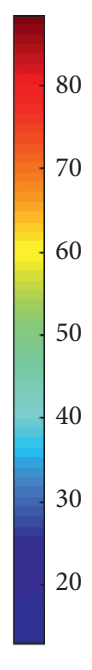

70

60

50

40

0

20

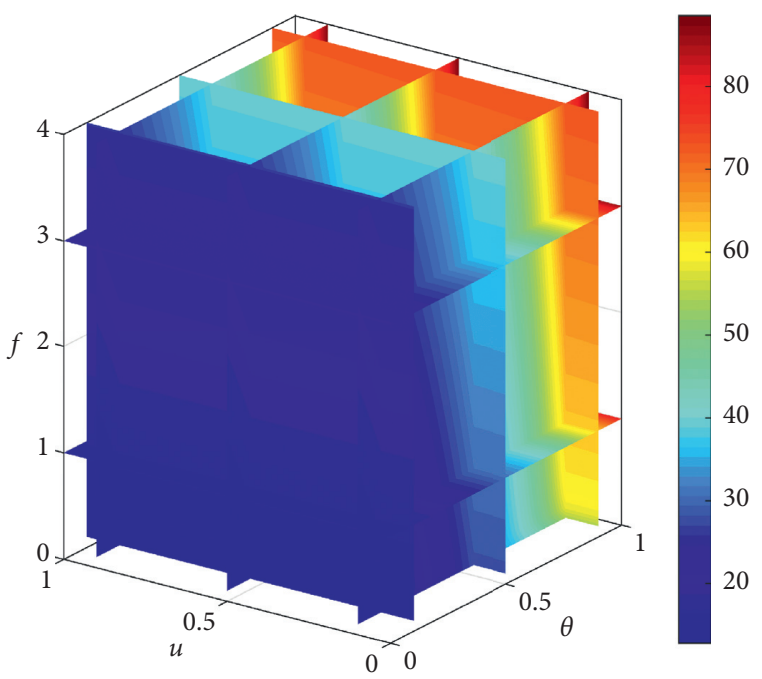

(b)

Figure 24: The effect of $u, \theta$, and $f$ on the profit of manufacturer 2. (a) Back. (b) Front.

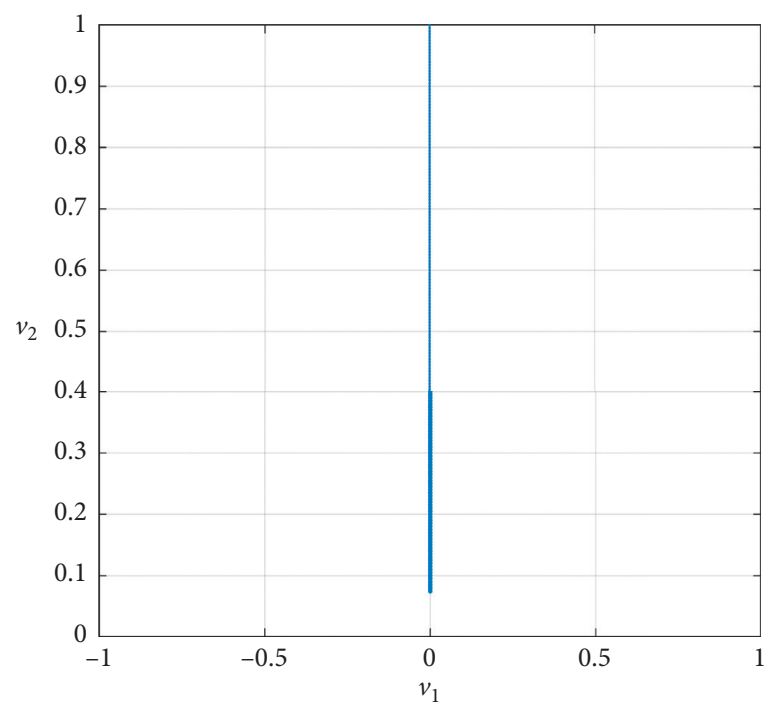

(a)

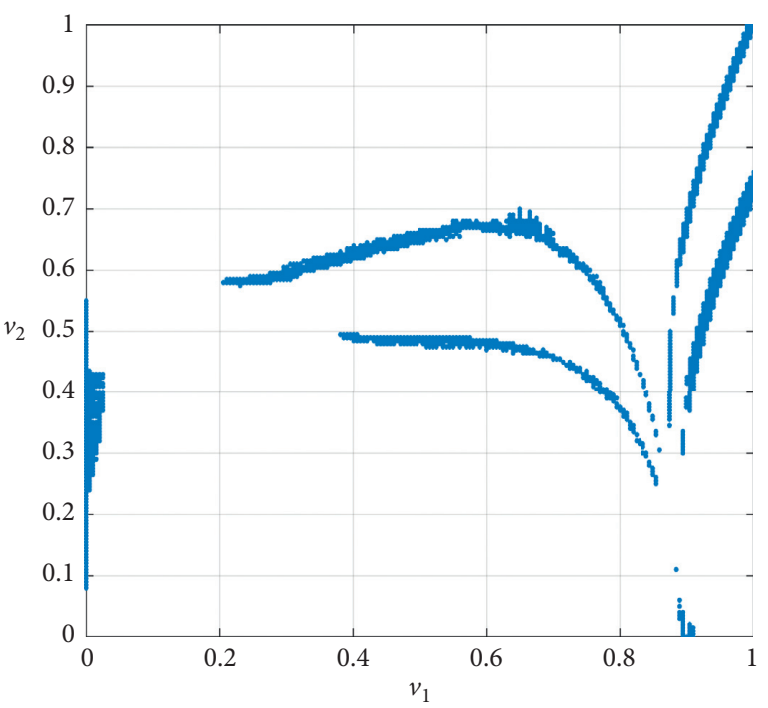

(b)

Figure 25: Continued. 


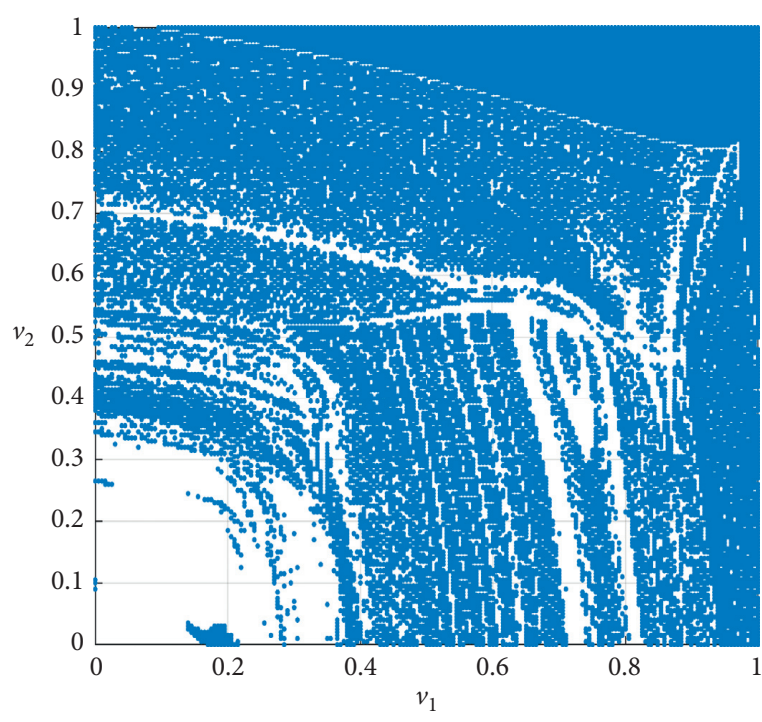

(c)

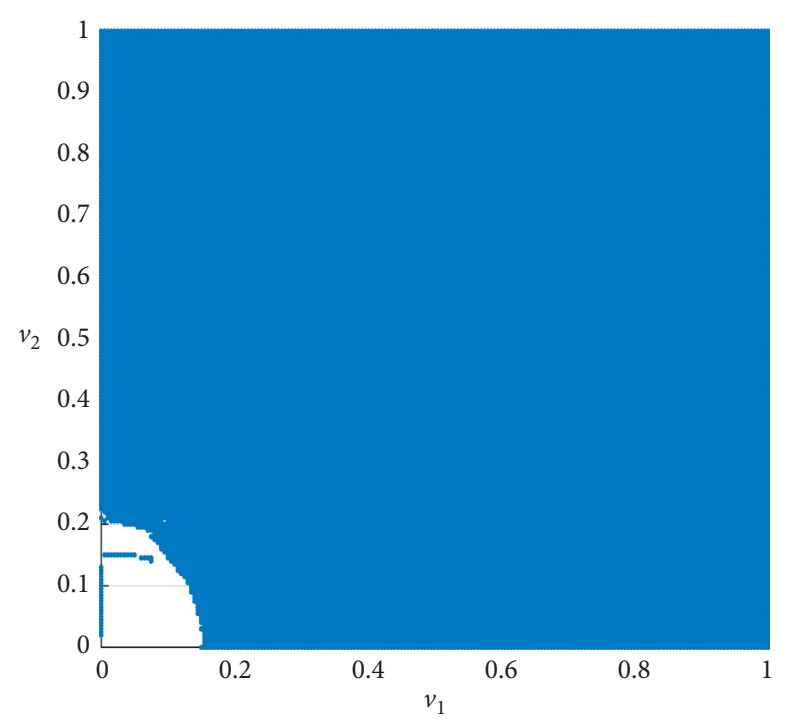

(d)

Figure 25: Pareto solutions with a change of $v_{1}$ and $v_{2}$ in different periods. (a) Period 1. (b) Period 5. (c) Period 10. (d) Period 100.

consider the decision in the period, $t$, and decision in the period, $t+1$. Thus, the dynamic adjustment model can be shown as follows:

$$
\left\{\begin{array}{l}
p_{1}(t+1)=p_{1}(t)+v_{1} p_{1}(t) \frac{\partial \Pi_{1}(t)}{\partial p_{1}(t)}+v\left(p_{1}(t+1)-p_{1}(t)\right), \\
p_{2}(t+1)=p_{2}(t)+v_{2} p_{2}(t) \frac{\partial \Pi_{2}(t)}{\partial p_{2}(t)}+v\left(p_{2}(t+1)-p_{2}(t)\right) .
\end{array}\right.
$$

We set the same parameters where $\alpha_{1}=10, \alpha_{2}=8, b=1$, $\theta=0.6, \lambda_{1}=0.7, \lambda_{2}=0.6, f=2, c_{1}=2, c_{2}=1.5, c_{1}=0.4$, $c_{2}=0.4, \quad \beta=10, \quad u=0.3, \quad$ and $\gamma=0.5$ and set $v_{1}=0.5, v_{2}=0.5$. Under this condition, the original system is in a chaotic state. Firstly, we introduce the parameter $g$ to control the system. Through numerical simulation, we draw the bifurcation diagram with the parameter $g$ increasing as follows.

From Figure 26, we can see that with the increase of parameter $g$, the price decision of the two manufacturers gradually gets out of chaos. And when $g=0.78$, the whole system enters a stable state, and the two manufacturers can have a stable price decision.

Then, we introduce the control parameter $v$ and add delayed feedback into the decision signal. Through numerical simulation, we draw the bifurcation diagram with the control parameter $v$ increasing as follows.

As is shown in Figure 27, the instability of the system is effectively eliminated after adding delayed feedback into the pricing decision. When $v$ is small, the state of the system is chaos. With the control parameter $v$ increasing, the state of the system is going into bifurcation and stable gradually. In the end, the system keeps stable when $v>0.34$, where the manufacturers can make effective decisions. We can draw the conclusion that delay control is a good way to control the

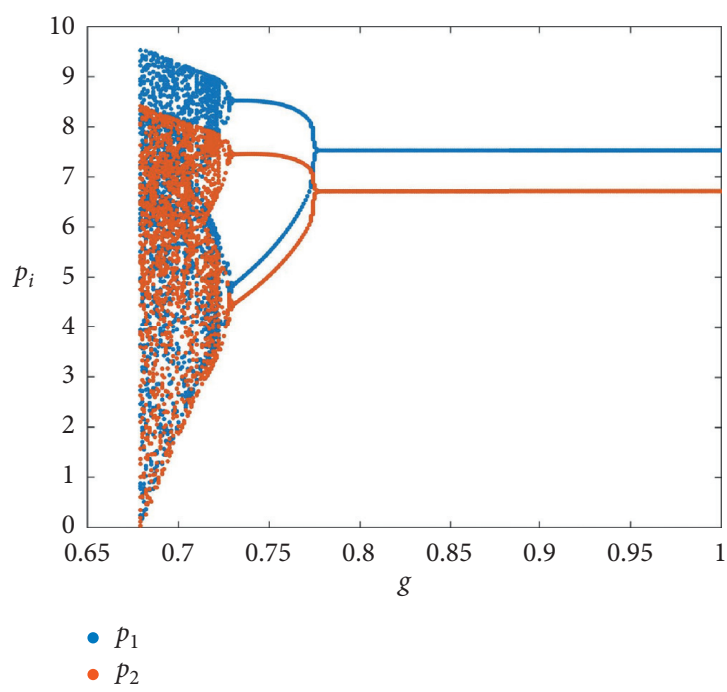

FIGURE 26: Bifurcation diagram with $g$ increasing.

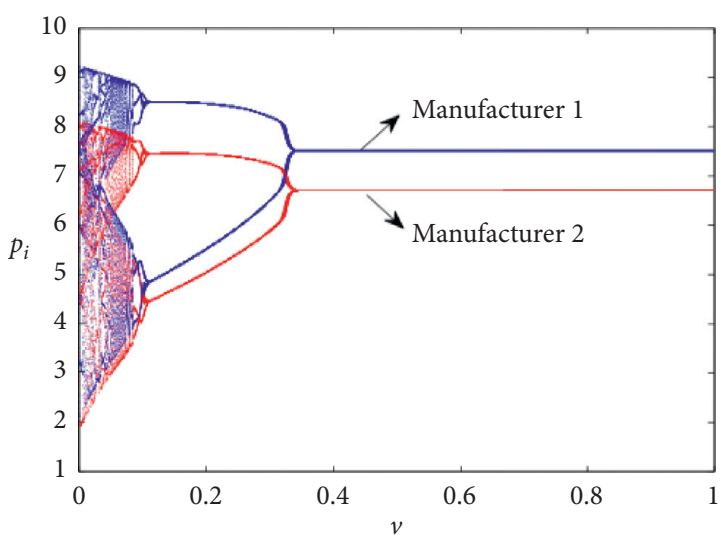

Figure 27: Bifurcation diagram with $v$ increasing. 
system based on the response of the manufacturers. Li and $\mathrm{Yu}[36]$ also prove that delay control can effectively solve the chaotic imagination that may arise in the development of the system. So, manufacturers can consider this method to solve the chaos phenomenon in the multiperiod system.

\section{Conclusion}

Considering the increasing environmental preoccupation, the potential economic benefits, and the legislation pressure, great attention has been paid to green innovation. In this paper, we focus on the activity of green innovation and build a model where the manufacturer will invest in green innovation to improve the product availability rate of recycled products and save the cost in the process of remanufacturing and the other manufacturers do not invest in green innovation. Besides, we take three stages in a cycle into consideration, that is, production/sale, recycling used production, and remanufacture/sale, and meanwhile, the government encourages enterprises to carry on the activity of recycling and gives a subsidy to enterprises according to the value of recycled used products. In the process of model solving, considering repeated games between two manufacturers in this system, a dynamic decision-making way is used. Then, we analyze the influence of the speed of adjustment on the stability of the system, the influence of the investment, and the government subsidy on the stability of the system and the effect of the investment and the government subsidy on the system. At the end of this research, we make chaos control. The conclusions we made are shown as follows [10, 35, 37-42]:

(1) The decision adjustment speed of players has a significant effect on stability, and in a long dynamic repeated game process, with the speed of decision adjustment increasing, the system enters into chaos at last. Besides, when the speed of decision adjustment exceeds the critical point of the bifurcation diagram, the profit of the manufacturer decreases and then enters a chaotic state. So, an appropriate adjustment speed should be adopted.

(2) The investment of the product availability rate of recycled products has no effect on the stable region of the system; with the level of subsidies increasing, the area of stable region decreases gradually, so the government needs to set an appropriate level of subsidies to maintain the stability of the system.

(3) Certain investment has a positive force for the product selling and recycling and the profit, and the government subsidy undoubtedly raises the profits of manufacturers and encourages the activity of recycling used products.

(4) We make chaos control through adjusting the decision method and the result shows that this method really has good control of the chaos of the system.

However, there are still some limitations. For example, the classic linear demand function is adopted in the model; however, there is a certain gap between this linear demand function and the reality; we do not take model structure into consideration. We leave this for the future.

\section{Data Availability}

The data used to support the findings of this study are available from the corresponding author upon request. The questionnaire data were acquired mainly through e-mail and filling out paper.

\section{Conflicts of Interest}

The authors declare no conflicts of interest.

\section{Acknowledgments}

This research was supported by the National Natural Science Foundation of China (No. 71571131).

\section{References}

[1] S. Turki, S. Didukh, C. Sauvey, and N. Rezg, "Optimization and analysis of a manufacturing-remanufacturing-transportwarehousing system within a closed-loop supply chain," Sustainability, vol. 9, no. 4, p. 561, 2017.

[2] X. Hong, K. Govindan, L. Xu, and P. Du, "Quantity and collection decisions in a closed-loop supply chain with technology licensing," European Journal of Operational Research, vol. 256, no. 3, pp. 820-829, 2017.

[3] P. D. Giovanni and G. Zaccour, "A two-period game of a closed-loop supply chain," European Journal of Operational Research, vol. 232, pp. 22-40, 2014.

[4] H. Krikke, I. 1. Blanc, and S. van de Velde, "modularity and the design of closed-loop supply chains," California Management Review, vol. 46, no. 2, pp. 23-39, 2004.

[5] J. D. Abbey and V. D. R. Guide, "A typology of remanufacturing in closed-loop supply chains," International Journal of Production Research, vol. 56, no. 1-2, pp. 374-384, 2018.

[6] Y. Xiong, Q. Zhao, and Y. Zhou, "Manufacturer-remanufacturing vs supplier-remanufacturing in a closed-loop supply chain," International Journal of Production Economics, vol. 176, pp. 21-28, 2016.

[7] J. Ma and W. Ren, "Complexity and Hopf bifurcation analysis on a kind of fractional-order IS-LM macroeconomic system," International Journal of Bifurcation and Chaos, vol. 26, no. 11, Article ID 1650181, 2016.

[8] M. E. Porter and V. D. Linde, "Green and competitive," Harvard Business Review, vol. 73, no. 5, pp. 120-134, 1995.

[9] X. Xie, J. Huo, G. Qi, and K. X. Zhu, "Green process innovation and financial performance in emerging economies: moderating effects of absorptive capacity and green subsidies," IEEE Transactions on Engineering Management, vol. 63, no. 1, pp. 101-112, 2016.

[10] M. Ley, T. Stucki, and M. Woerter, "The impact of energy prices on green innovation," The Energy Journal, vol. 37, no. 1, pp. 41-75, 2016.

[11] E. L. Olson, "Perspective: the green innovation value chain: a tool for evaluating the diffusion prospects of green products," Journal of Product Innovation Management, vol. 30, no. 4, pp. 782-793, 2013.

[12] H. K. Chan, R. W. Y. Yee, J. Dai, and M. K. Lim, "The moderating effect of environmental dynamism on green 
product innovation and performance," International Journal of Production Economics, vol. 181, pp. 384-391, 2016.

[13] J.-B. Sheu and Y. J. Chen, "Impact of government financial intervention on competition among green supply chains," International Journal of Production Economics, vol. 138, no. 1, pp. 201-213, 2012.

[14] H. Ashkan, "Competition of two green and regular supply chains under environmental protection and revenue seeking policies of government," Computers \& Industrial Engineering, vol. 82, pp. 103-114, 2015.

[15] H. Peng, "Optimal subsidy policy for accelerating the diffusion of green products," Journal of Industrial Engineering \& Management, vol. 6, no. 2, pp. 673-679, 2013.

[16] C. Wang, P.-y. Nie, D.-h. Peng, and Z.-h. Li, "Green insurance subsidy for promoting clean production innovation," Journal of Cleaner Production, vol. 148, pp. 111-117, 2017.

[17] S. Subrata, S. Majumder, and I. E. Nielsen, "Is it a strategic move to subsidized consumers instead of the manufacturer?" IEEE Access, vol. 7, pp. 169807-169824, 2019.

[18] I. E. Nielsen, S. Majumder, S. S. Sana, and S. Saha, "Comparative analysis of government incentives and game structures on single and two-period green supply chain," Journal of Cleaner Production, vol. 235, pp. 1371-1398, 2019.

[19] Z. Huang, G. Liao, and Z. Li, "Loaning scale and government subsidy for promoting green innovation," Technological Forecasting and Social Change, vol. 144, pp. 148-156, 2019.

[20] G. Li, M. Reimann, and W. Zhang, "When remanufacturing meets product quality improvement: the impact of production cost," European Journal of Operational Research, vol. 271, no. 3, pp. 913-925, 2018.

[21] J. P. Gayon, S. Vercraene, and S. D. P. Flapper, "Optimal control of a production-inventory system with product returns and two disposal options," European Journal of Operational Research, vol. 262, no. 2, pp. 499-508, 2017.

[22] T. Maiti and B. C. Giri, "Two-way product recovery in a closed-loop supply chain with variable markup under price and quality dependent demand," International Journal of Production Economics, vol. 183, pp. 259-272, 2016.

[23] T. Hosoda and S. M. Disney, "A unified theory of the dynamics of closed-loop supply chains," European Journal of Operational Research, vol. 269, no. 1, pp. 313-326, 2017.

[24] J. Tang, B.-Yi Li, K. W. Li, Z. Liu, and J. Huang, "Pricing and warranty decisions in a two-period closed-loop supply chain," International Journal of Production Research, vol. 58, no. 6, pp. 1688-1704, 2020.

[25] Z. Liu, K. W. Li, B.-Y. Li, J. Huang, and J. Tang, "Impact of product-design strategies on the operations of a closed-loop supply chain," Transportation Research Part E: Logistics and Transportation Review, vol. 124, p. 7591, 2019.

[26] W. Wang, J. Ding, and H. Sun, "Reward-penalty mechanism for a two-period closed-loop supply chain," Journal of Cleaner Production, vol. 203, pp. 898-917, 2018.

[27] B. Bao and J. Ma, "Dynamic game behavior of retailers considering the quality of substitute products based on delay decision," International Journal of Bifurcation and Chaos, vol. 27, no. 13, Article ID 1750206, 2017.

[28] J. Ma and Z. Guo, "The parameter basin and complex of dynamic game with estimation and two-stage consideration," Applied Mathematics and Computation, vol. 248, pp. 131-142, 2014.

[29] J. Ma, W. Lou, and Y. Tian, "Bullwhip effect and complexity analysis in a multi-channel supply chain considering price game with discount sensitivity," International Journal of Production Research, vol. 57, no. 17, pp. 5432-5452, 2019.
[30] J. Ma and H. Tu, "Analysis of the stability and Hopf bifurcation of money supply delay in complex macroeconomic models," Nonlinear Dynamics, vol. 76, no. 1, pp. 497-508, 2014.

[31] J. Ma and L. Xie, "The comparison and complex analysis on dual-channel supply chain under different channel power structures and uncertain demand," Nonlinear Dynamics, vol. 83, no. 3, pp. 1379-1393, 2016.

[32] D. Dai, F. Si, and J. Wang, "Stability and complexity analysis of a dual-channel closed-loop supply chain with delayed decision under government intervention," Entropy, vol. 19, no. 11, p. 577, 2017.

[33] W. Lou and J. Ma, "Complexity of sales effort and carbon emission reduction effort in a two-parallel household appliance supply chain model," Applied Mathematical Modelling, vol. 64, pp. 398-425, 2018.

[34] Y. Choo and D. Kim, "Simple proof of jury test for complex polynomials," IEICE Transactions on Fundamentals of Electronics, Communications and Computer Sciences, vol. E93-A, no. 2, pp. 550-552, 2010.

[35] A. Y. Wang, "Adaptive parameter adjustment of dynamical systems for chaos," in Proceedings of the International Conference on Informatics, Cybernetics, and Computer Engineering Melbourne, 2011.

[36] L. Li and F. Yu, "New results on delay-dependent stability for time-delay chaotic systems via time-delay feedback control," in Proceedings of the 2009 Chinese Control and Decision Conference, Guilin, China, June 2009.

[37] I. E. Sana, S. Majumder, and S. Saha, "Game-theoretic analysis to examine how government subsidy policies affect a closedloop supply chain decision," Applied Sciences-Basel, vol. 10, pp. 1-23, 2019.

[38] J. Ma and H. Wang, "Complexity analysis of dynamic noncooperative game models for closed-loop supply chain with product recovery," Applied Mathematical Modelling, vol. 38, no. 23, pp. 5562-5572, 2014.

[39] L. Xie, J. Ma, and H. Han, "Implications of stochastic demand and manufacturers' operational mode on retailer's mixed bundling strategy and its complexity analysis," Applied Mathematical Modelling, vol. 55, pp. 484-501, 2018.

[40] L. Xie, J. Ma, and M. Goh, "Supply chain coordination in the presence of uncertain yield and demand," International Journal of Production Research, pp. 1-17, 2020.

[41] J. Ma, Y. Hou, W. Yang, and Y. Tian, "A time-based pricing game in a competitive vehicle market regarding the intervention of carbon emission reduction," Energy Policy, vol. 142, p. 111440, 2020.

[42] B. Bao, J. Ma, and M. Goh, "Short- and long-term repeated game behaviours of two parallel supply chains based on government subsidy in the vehicle market," International Journal of Production Research, pp. 1-24, 2020. 